\title{
Technical Indicators for the Comparison of Power Network Development in Scenario Evaluations
}

\author{
Maria Dicorato (D), Gioacchino Tricarico*(D), Giuseppe Forte (D) and Francesca Marasciuolo \\ Politecnico di Bari-Department of Electrical and Information Engineering, Via E. Orabona, 4, 70125 Bari, Italy; \\ maria.dicorato@poliba.it (M.D.); giuseppe.forte@poliba.it (G.F.); francesca.marasciuolo@poliba.it (F.M.) \\ * Correspondence: gioacchino.tricarico@poliba.it
}

check for updates

Citation: Dicorato, M.; Tricarico, G.; Forte, G.; Marasciuolo, F. Technical Indicators for the Comparison of Power Network Development in Scenario Evaluations. Energies 2021, 14, 4179. https://doi.org/10.3390/ en14144179

Academic Editor: Ignacio Mauleón

Received: 31 May 2021

Accepted: 7 July 2021

Published: 10 July 2021

Publisher's Note: MDPI stays neutral with regard to jurisdictional claims in published maps and institutional affiliations.

Copyright: (C) 2021 by the authors. Licensee MDPI, Basel, Switzerland. This article is an open access article distributed under the terms and conditions of the Creative Commons Attribution (CC BY) license (https:// creativecommons.org/licenses/by/ $4.0 /)$.

\begin{abstract}
The problem of electric network expansion has different implications concerning the definition of criteria for the comparison of different candidate projects. Transmission expansion planning usually involves a set of economic and technical influences on market framework and on network operation over defined scenario evolutions, or even combining generation and transmission planning, although the application to real-sized networks usually implies cost-benefit analysis. In this paper, a methodology for performance analysis of a set of network development projects is proposed, including zonal market framework and load flow analysis, in order to individuate possible candidate projects and their influence on active power losses, admissible load increase and admissible renewable generation increase. Those merit indicators are compared among candidate projects by means of Analytic Hierarchy Process (AHP) method, aiming at determining the most promising solution under different weights of criteria. Moreover, the influence of network development investment cost on project selection is assessed by means of an extension of AHP. The procedure is applied to yearly operation of NREL-118 test system.
\end{abstract}

Keywords: transmission network; network development project; load increase; renewable increase; analytic hierarchy process

\section{Introduction}

Studies of network development planning aim to analyze the interaction of grid configuration, generation and demand. Providing demand envisions, the scheduling goal is to deal with generation evolution (e.g., replacing out-to-date technologies with renewables and innovative ones), combined with demand load trend evolution taking into account economical, reliability, continuity and environmental factors. Further, network developing analysis represents a crucial issue due to the analytics intricacy and the big data management. These reasons have brought the definition of Transmission Evolution Planning (TEP) and Generation Evolution Planning (GEP) or combined G\&TEP. With regard to TEP, the Transmission System Operators (TSOs) must consider the uncertainty of future framework of load demand required or renewable generation penetration satisfying technical constrains and ensuring reliability and security, by assessing branch doubling or new grid assets.

G\&TEP is overwhelming modelled, as mono- or bi-level programming-based optimization methods to minimize costs, and it is formulated as Mixed Integer Linear Programming (MILP) [1-4], Mixed Integer Nonlinear Programming (MINP) [5] or Robust Optimization [6]. Generation and transmission investment costs are the essential terms present in the objective function for all the approaches [1-6] whereas additional aspects involve operating costs, expected energy not served (EENS), losses cost, load shedding costs.

TEP mathematical optimization methods can be grouped in two main categories: programmingbased and heuristic optimizations. Linear programming (LP) [7-11], MILP [12-17], robust optimization (RO) [18-21] or games theory [22] are the spread methods of the first group. 
Instead heuristics can include K-medoids [23], Gbest-Guided Artificial Bee Colony [24], Particle Swarm Optimization [25,26], multi-criteria decision making and differential evolution [27] social spider algorithm [28], evolutionary algorithms [29], semi-definitive programming and branch and bound [30], symbiotic organism algorithm [31], or combined search space reducer and bat-inspired algorithm [32]

As regards objective functions, in TEP new transmission line investment costs are usually considered, but additional operating costs or penalties could be included, such as generation operating costs $[10,19,24,25]$, matched with unserved energy costs as in $[9,20,21,23,32]$, or with load shedding as in $[11,14,15]$. Other works consider loss-of-load probability and load curtailment costs [13], renewable curtailment costs [8], load shedding and renewable curtailment costs [16], losses penalty factor [30], or operational costs, generation curtailment and load shedding costs [17]. Few works neglect generation operating costs in objective function but embed new factors as in [26] where weighted vulnerability factors are introduced to optimize the system security, or in [27] whose purpose is to avoid congestions by means of a penalty factor. A novel case of investment costs omission is evaluated in [7], rather the focus is on the generation costs including fuel, O\&M and CO2 costs. In multi-level TEP optimization the investment costs are considered in the last level. Detailed market aspects are modeled in [22] where the first-level optimization pursues generation costs minimization and consumer surplus maximization, the second-level aims at maximizing zonal generation and consumer surpluses and congestion rent earned by the TSO, while the third-level goal is to minimize investment costs and maximize global generation and consumer surpluses. The authors of [18] minimize the generation and load shedding costs in the level-I, and investment costs in level-II.

A crucial perspective in the TEP optimization constraints is the network model. The most employed formulation is the DC load flow (LF) $[1-3,6,9-19,21-23,27,28,31]$, in few papers the losses have been embedded by means of quadratic expression in the DC formulation $[5,29,32]$. Nevertheless, other approaches exploit power transfer distribution factors (PTDFs) [4,7,8], shifting factors [11,26], economic dispatch [20] or power balance [29] but all the approaches omit the behavior of losses. AC LF formulation is adopted in [25] and [30]: the first one compares the AC optimal power flow (OPF) model with DC-TEP formulation considering piecewise linear losses, while the second represents the losses as difference between generation and load. As reported above, the TEP optimization methods focus on economic terms, with simplified network models to reduce formulation complexity and reduce computational cost. However, as demonstrated in [25] the AC OPF solution requires higher capacity installation and lower operating costs compared to the DC-TEP ones. Besides, [33] investigates the influence of losses model in the TEP solution, underlining the variation in investment costs proving that in large-scale systems the losses have a relevant impact.

A separate set of approaches, guided by TSO applications, involve solution techniques of TEP problem different from optimization. The combination of DC-OPF and cost-benefit analysis (CBA) is the common framework employed to evaluate the candidate project selection. The CBA is conducted by means of: wind spillage and production costs indices [34]; the comparison with and without weighted environmental aspects indices [35]; present-value, welfare, investment costs indices [36]; investment costs, congestion costs and risk costs minima [37]; reliability indices and investment, operational and risk costs minima. In [38] ENTSO-E CBA is evaluated through a software called SCANNER. In [39] electrical market with Multi-Area Power-Market Simulator software is considered, with detailed model of intermittent and hydro generation, comparing results by CBA based on investment costs, transmission and generation capacity. A flow-based optimization market capacity is proposed in [40] exploiting PTDFs and remaining available margins (RAMs) through the corridors. Moreover, phase shifter transformers (PSTs) are connected over cross-zonal branch to adjust RAMs by means of an optimization. The authors of [41] developed a flow-based methodology, solving Day-Ahead Market (DAM) and AC LF to state the network operating conditions and evaluating the economic benefits introduced 
by candidate projects according to losses, generation redispatching, renewable and load curtailment reductions.

Nowadays a worldwide green energy generation and consumption transition is developing and TSOs are organizing a long-term TEP forecasting renewable generation and demand growth. In the field of scientific research this issue is tackled by multi-scenario $[2,7,12,14,20,23,25,35,38,39]$, scenario clustering $[13,16,17]$ or multi-year approach $[5,6,9,18,19,21,36,37]$. In the first, framework generation and load are uncorrelated, in the second the gathering of scenarios is related to cost minima, while in the last the increases are correlated and predefined. The considered network uncertainties are mainly represented by intermittent renewable generation and load demand.

The power grid size is a relevant factor in terms of TEP computational cost and method extension to real power systems. Some works exploit test networks, such as 4-bus [22,40], Garver 6-bus [24], 9-bus [1], IEEE 24-bus [4,9,25,27], IEEE 30-bus [6], IEEE 118-bus $[13,17,18,41]$ and 120-bus [16]. TEP methods are applied to real network models as well, such as Australian 24-bus [7], German zonal market [8], Romanian [15], European Zonal Market [23,35], small-scale China [26], Northern Europe [38,39], U.S. 240-bus [2] and 3000-bus Northern China [34]. Other works perform comparisons of different networks, involving test networks of different sizes $[10,19,20,28]$, or matching simple test system with real network models such as 93-bus Colombian [12], 46-bis and 87-bus Southern Brazilian [28-32], Iranian Power grid [5,37].

Simulation time reduction also depends on the number of candidate projects to evaluate, and an established technical analysis is helpful to reduce the set dimension embedding the ones with higher benefits. For this purpose, in [7] the set is determined according to RES penetration, in [9] a relaxed version of the TEP problem is solved to quantify the investment pool with most benefits. Moreover, in [10] following the load flow results the reinforcement for congested corridors is considered and locational marginal price advantages for new line addition, in [20] a method based on long- and short-terms network uncertainties is developed to pinpoint the candidate investments, and in [23] different typology of candidate projects are determined according to the potential benefits introduced. For candidate selection, in [29] a load and an angle performance index is defined, in [31] a search space reducer algorithm is solved, in [34] cost-benefit incremental relationship and sensitivity factor of branch capacity and admittance are evaluated, in [35] the probability of branch overload is considered, while in [41] an equivalent positive and negative critical overload duration is introduced. Further methods, applications, and evaluations are reported in the review papers [42,43].

There are few papers that include N-k security criteria in TEP assessment. In particular, optimization problems are faced including $\mathrm{N}-1$ security constraint in the formulation $[5,6,29,40]$, or involving both $\mathrm{N}-1$ and $\mathrm{N}-2$ security criteria generating a set of contingency scenarios [4]. The authors of $[10,44,45]$ evaluate an N-k security in the second stage of the procedure in order to define the set of candidate projects and/or to obtain optimal solution, whereas in [37] a risk index is defined including the line outage probability.

From literature analysis, it stems that the formulation of a TEP problem has several facets that are hardly caught in the presence of a real-size network, where cost-benefit analysis of single development projects is usually carried out [46,47]. Moreover, different implications of the development projects should be assessed in the form of scenario analysis. In order to perform useful comparison among different projects by accounting non-commensurable quantities, multi-criteria analysis can be adopted, with particular reference to Analytic Hierarchy Process (AHP) due to high flexibility and applicability [48,49]. This technique has found application in power system problems such as Generation expansion planning, in a multi-objective model with detailed network representation in [50] and encompassing financial, technical, environmental and social aspects in [51], or distribution system planning [52]. However, TEP problems represent a field of application of AHP for multi-criteria analysis. In particular, application of test network involve IEEE 24-bus test system in [53], where a multi-objective optimization involving congestion cost, investment 
cost, probabilistic reliability, anti-competition and anti-flexibility indices allows to obtain the Pareto front and it is supported by AHP and TOPSIS to determine the best solution, in [54], exploiting a two-stage TEP algorithm where cost minimization results are analyzed with AHP considering congestion cost, consumer cost, power losses and voltage deviations, and in [27], where dynamic evolution technique is underpinned by AHP for ranking the best compromise solution. Moreover, in [55] indices of economy, safety, flexibility and vulnerability are taken as criteria of fuzzified AHP method with different comprehensive weights for IEEE 6-bus network with different planning schemes, whereas in [56] location marginal prices from AC load flow in IEEE 9-bus system are used for individuating candidates combined with AHP. As regards real network applications, in [57] a combination of AHP and entropy weight is adopted to evaluate three candidate projects by means of indices of safety (including N-1 and N-2 security ones) and reliability, economy and efficiency, coordination and flexibility, social aspects and risk control. Whereas in [58] a Brazilian network is analyzed considering AHP for probabilistic, strategic, financial, externalities and enterprise risk, and in [59] Paraguay transmission system expansions are analyzed with AHP considering operation and inversion cost, power losses, line length and project financing. It can be noted that the analysis of AHP in TEP has seldom accounted for evolution scenarios of load and renewables, and methods are focused on network with limited extension.

In this paper, a methodology for performance analysis of a portfolio of network development projects is proposed, in order to evaluate the subset of projects towards which the TSO should focus its realization efforts according to positive implications on different technical aspects and limited economic effort. In particular, the methodology aims at assessing zonal market framework, with linear bids and inelastic demand, and AC LF analysis, in the base case network to individuate possible candidate projects. The same tools are exploited in the presence of network development candidate project, in order to calculate merit indicators on active power losses, admissible load increase and admissible renewable generation increase. These merit indicators are compared among candidate projects by means of Analytic Hierarchy Process method, in order to determine the most promising solution under different weights of criteria, representing an evaluation of various evolution scenarios. A further analysis implies the influence of investment cost as economic merit indicator, and its inclusion in AHP is carried out in order to point out the impact of economic efforts on the multi-criteria decision framework. The procedure is applied to NREL-118 test system.

The contributions of this paper can be synthesized as follows:

- The full network representation by means of AC LF evaluating active e reactive power flow and effective power losses.

- The evaluation of candidate projects set according to base case network operating condition within one year of observation.

- The adoption of AHP approach evaluating the candidate projects according to different weighted indices of losses reduction, admissible load increase, admissible renewable penetration, and investment effort.

- Differently for cost-benefit analysis dealt with in [41], the procedure does not involve an economic quantification of technical benefits, whereas it is aimed at comparing heterogeneous implications of network development projects in a normalized way.

The remainder of the paper is organized as follows. Section 2 is devoted to the description of the multi-stage methodology for network operation analysis, candidate project selection, performance indicator definition and comparison technique. The test system and the base case analysis are presented in Section 3, whereas the network development projects are assessed in Section 4 along with their comparison. Conclusions are drawn in Section 5. 


\section{Methodology}

The determination of the network development initiative follows a multi-step methodology, synthesized in the following points:

- Study of base case operation according to techno-economic programming over a defined time horizon.

- Individuation of candidate network development projects, able to produce effects on system behavior.

- Carrying out of scenario analysis for each candidate project and determination of the merit indicators.

- Selection of the most promising projects.

\subsection{Power System Techno-Economic Operation}

In order to evaluate the operating conditions of the considered power system, technical and economic considerations should be accounted. The combination of these aspects can be assessed in optimal power flow analysis [60], however in the outline of an unbundled energy sector, the presence of energy markets should be considered. Therefore, the adopted method to determine power system operation is structured as follows.

For each operating condition to be analyzed, represented by the $t$-th time step in the considered time window, the procedure involves the solution of a zonal energy market with quadratic generation bids and inelastic load demand, whose formulation can be synthesized as follows:

$$
\min \sum_{z=1}^{N_{Z}} \sum_{g=1}^{N_{G}} \beta_{g, b} \beta_{b, z}\left(\alpha_{g} P_{g}(t)+\frac{1}{2} \gamma_{g} P_{g}^{2}(t)\right) \forall t=1, \ldots, N_{T}
$$

s.t.

$$
\begin{gathered}
\sum_{b=1}^{N_{B}} \sum_{g=1}^{N_{G}} \beta_{g, b} \beta_{b, z} P_{g}(t)-\sum_{b=1}^{N_{B}} \beta_{b, z} P D_{b}(t)-\sum_{k=1}^{N_{E}} \beta_{k, z} e_{k}(t)=0 \quad \forall t=1, \ldots, N_{T} \vee \forall z=1, \ldots, N_{Z} \\
0 \leq P_{g}(t) \leq a v_{g}(t) P_{g}^{\max } \quad \forall t=1, \ldots, N_{T} \vee \forall g=1, \ldots, N_{G} \\
-e_{k}^{\max } \leq e_{k}(t) \leq e_{k}^{\max } \forall t=1, \ldots, N_{T} \vee \forall k=1, \ldots, N_{E}
\end{gathered}
$$

where:

- $\quad N_{Z}$ is the number of market zones and $z$ is the zone index;

- $\quad N_{B}$ is the number of buses and $b$ is the bus index;

- $\quad N_{G}$ is the number of generators and $g$ is the generator index;

- $N_{E}$ is the number of interzonal connection and $k$ is the zonal interface index;

- $\quad N_{T}$ is the total amount of time step and $t$ is time step index;

- $\quad \beta_{g, b}$ is a binary parameter and it indicates if the $g$-th generator is connected (1) or not $(0)$ to the $b$-th bus;

- $\quad \beta_{b, z}$ is a binary parameter and it indicates if the $b$-th bus is connected (1) or not (0) to the $z$-th zone;

- $\quad \beta_{k, z}$ indicates if the $k$-th power exchange is entering (1), exiting $(-1)$ or not connected (0) to the $z$-th zone;

- $\quad \beta_{k, z}$ is a binary parameter and it indicates if the $k$-th interzonal exchange is connected to the $z$-th zone (assuming 1 or -1 if the positive exchange is exiting or entering the $z$-th zone), whereas it is 0 if the $k$-th interzonal exchange does not involve the $z$-th zone;

- $\quad P D_{b}(t)$ is the inelastic active power demand at the $b$-th bus at $t$-th time;

- $\quad \alpha_{g}$ and $\gamma_{g}$ are the linear and quadratic bid coefficient of the $g$-th generator;

- $a v_{g}(t)$ is the availability of the $g$-th generator at $t$-th hour;

- $\quad P_{g}^{\max }$ is the rated active power of the $i$-th generator;

- $\quad e_{k}^{\max }$ is the rated active power exchange of the $k$-th interzonal border; 
- $\quad P_{g}(t)$ is the generated power of the $g$-th generator at $t$-th time;

- $e_{k}(t)$ is the power exchange at the $k$-th zonal interface.

In particular, Equation (2) represents the power balance constraint, Equation (3) explicates the generator technical limits, and Equation (4) introduces the zonal interface limit constraints.

The absence of generators technical minimum avoids the presence of block order bids that involve entirely accepted or rejected bids conditions according to the market clearing price, for each hour. These bids entail a Mixed Integer Linear Programming with binary variables that state all-or-nothing constraints, which in turn leads to a counterintuitive market solution called Paradoxically Accepted/Rejected Blocks, described in [61,62].

It should be remarked that the maximum interzonal power exchange across the $k$-th border $e_{k}^{\max }$ is strictly related to the active power flow rating $R P_{l}$ of all the $l$-th branches constituting the $k$-th border. For instance, it could represent the Available Transfer Capacity (ATC) value in $\mathrm{N}$ or $\mathrm{N}-1$ conditions, or come from other security considerations.

The output of the energy market is represented by the power generation plan of the dispatchable generation present in the power system able to minimize the objective (e.g., reduce the generation cost) in the presence of zonal constraints. However, the impact on the behavior of network elements should be assessed as well. Therefore, a steady-state network analysis is performed, considering the distributed load flow framework with full AC formulation, developed as follows:

$$
\begin{gathered}
\sum_{g=1}^{N_{G}} \beta_{g, b} \bar{P}_{g}(t)-P D_{b}(t)-\sum_{c=1}^{N_{B}} y_{b c} V_{b}(t) V_{c}(t) \cos \left(\theta_{b}(t)-\theta_{c}(t)+\phi_{b c}\right)=0 \quad \forall t=1, \ldots, N_{T} \vee \forall b=1, \ldots, N_{B} \\
\sum_{g=1}^{N_{G}} \beta_{g, b} Q_{g}(t)-Q D_{b}(t)-\sum_{c=1}^{N_{B}} y_{b c} V_{b}(t) V_{c}(t) \sin \left(\theta_{b}(t)-\theta_{c}(t)+\phi_{b c}\right)=0 \quad \forall t=1, \ldots, N_{T} \vee \forall b=1, \ldots, N_{B} \\
\text { s.t. } \bar{P}_{g}(t)=P_{g}(t)+\omega_{g} L o(t) \forall t=1, \ldots, N_{T} \vee \forall g=1, \ldots, N_{G} \\
L o(t)=\sum_{l=1}^{N_{L}} L_{l}(t)=\sum_{l=1}^{N_{L}} \operatorname{Re}\left\{\frac{\left|\beta_{l, b} v_{b}(t)-\beta_{l, c} v_{\mathcal{c}}(t)\right|^{2}}{r_{l}-j x_{l}}\right\} \\
v_{b}(t)=V_{b}(t) e^{j \theta_{b}(t)}, v_{c}(t)=V_{c}(t) e^{j} \theta_{c}(t) \quad \forall\{b, c\}=1, \ldots, N_{B}, b \neq c \\
0 \leq \omega_{g} \leq 1 \quad \forall g=1, \ldots, N_{G} \\
\sum_{g=1}^{N_{G}} \omega_{g}=1
\end{gathered}
$$

where:

- $\quad N_{L}$ is the total number of branches and $l$ is the branch index;

- $\bar{P}_{g}(t)$ is the total generated active power by the $g$-th generator;

- $y_{b c}$ and $\phi_{b c}$ are amplitude and phase of the nodal admittance between $b$ and $c$ buses (coming from the construction of the $N_{B} \cdot N_{B}$ nodal admittance matrix $Y$;

- $\quad V_{b}(t)$ and $\theta_{b}(t)\left(V_{c}(t)\right.$ and $\left.\theta_{c}(t)\right)$ are amplitude and phase of nodal voltage at $b$-th (c-th) bus at $t$-th time step;

- $\omega_{g}$ is the loss participation factor of $g$-th generator;

- $L o(t)$ is the system total active power loss at time step $t$;

- $\quad L_{l}(t)$ is the amount of active power losses across $l$-th branch at $t$-th time step;

- $\quad \beta_{l, b}$ and $\beta_{l, c}$ are binary parameters and they indicate if the $b$-th (c-th) bus is connected (1) or not (0) to the $l$-th branch;

- $\quad r_{l}$ and $x_{l}$ are the resistance and reactance values of the $l$-th branch;

- $j$ is the imaginary unit. 
The distributed load flow is considered in order to share the burden of active power losses balance-not considered in zonal energy market solution-with a limited though diffused stress on the selected generators.

In outcome of the analysis, further than the determination of nodal voltage, the amount of active, reactive and apparent power flowing across the $l$-th branch, named $F P_{l}(t), F Q_{l}(t), F S_{l}(t)$, are determined from the following complex equation:

$$
F S_{l}(t)=F P_{l}(t)+j F Q_{l}(t)=\beta_{l, b} v_{b}(t) \cdot\left[\frac{\beta_{l, b} v_{b}(t)-\beta_{l, c} v_{c}(t)}{r_{l}-j x_{l}}+y_{l} \beta_{l, b} v_{b}(t)\right]^{*}
$$

where the superscript * stands for complex conjugate value

This double-layer analysis is performed for each time step of the considered time horizon.

\subsection{Selection of the Candidate Projects}

From the power system techno-economic operation analysis, and particularly from the determination of power flowing through branches, the loading analysis of network connection can be carried out.

In particular, for each $l$-th branch, the loading factor in each time step $B L_{l}(t)$ is determined as the ratio of absolute value of power flow $F S_{l}(t)$ on active power flow rating $R P_{l}$, as follows:

$$
B L_{l}(t)=\left|F S_{l}(t)\right| / R P_{l} \quad \forall t=1, \ldots, N_{T}
$$

For the base case, the average value of the loading factor $A B L_{l}$ throughout the considered time horizon and a duration curve of loading factor (sorting the values from the highest to the lowest, irrespective of the time step position in the horizon) can provide synthetic evaluation of the operation stress of the $l$-th branch, thus individuating the paths that would benefit more from a reinforcement project. The formulation of $A B L_{l}$ can be generalized as follows:

$$
A B L_{l}=\frac{1}{N_{T}} \cdot \sum_{t=1}^{N_{T}} \Delta T(t) \cdot B L_{l}(t)
$$

According to the adopted operation planning standard, the overloaded branches can be individuated if the power flow exceeds the rating value by a suitable margin $\varepsilon$; therefore, no overload is observed if the following condition is satisfied

$$
B L_{l}(t)>1+\varepsilon \quad \forall t=1, \ldots, N_{T} \forall l=1, \ldots, N_{L}
$$

From the theoretical framework of the zonal market, it could be expected that more stressed connections are placed across the zones and not within each zone. Therefore, a first selection is made considering the doubling of existing connections across each couple of zones.

However, further connection lines could be individuated as well, in order to improve the network meshing, providing different paths for power routing that could increase the efficiency, although they could represent a more costly solution. A second selection of candidate projects involves new connections between couple of nodes pertaining to different zones, not interested by existing line or existing market zone connections.

\subsection{Scenario Analysis of Development Projects}

The impact of the candidate project is assessed by means of a PINT approach, therefore each project is analyzed separately, as described in the following.

Differently from the determination of techno-economic benefits at target years according to defined evolution of system generation and demand, the proposed approach aims at determining the effect of the presence of development projects in the considered system through technical merit indicators.

A first indicator is represented by the variation of total active power losses induced by the presence of the $x$-th candidate project. In order to perform this estimation, the energy 
market in Equations (1)-(4) is solved accounting for the presence of the $x$-th development project, affecting the inputs of the rated active power exchange $e_{k, x}^{\max }$, and the load flow analysis in Equations (5)-(11) is carried out considering the influence of the $x$-th candidate project on the nodal admittance matrix $Y_{x}$. Therefore, the global power system operation is varied in each $t$-th time step. The indicator $I L_{x}$ quantifies the energy losses reduction benefits, for the $x$-th development project over $N_{T}$ observation period, with respect to the base case network, and it can be expressed as follows:

$$
I L_{x}=\sum_{t=1}^{N_{T}} \sum_{l=1}^{N_{L}} \Delta T(t) \cdot L o_{l}(t)-\sum_{t=1}^{N_{T}} \sum_{l=1}^{N_{L}} \Delta T(t) \cdot L o_{l, x}(t) \quad \forall x=1, \ldots, N_{X}
$$

where:

- $\quad N_{X}$ is the total number of candidate development projects and $x$ is the candidate project index;

- $\quad L o_{l, x}(t)$ represents the $l$-th branch active losses in the presence of $x$-th candidate project at time step $t$.

Furthermore, in order to investigate the effect of the project on possible evolution of the generation and demand, and particularly on the attainment of targets for increased energy service for users and reduced environmental impact of power system, the considered power system is subject to increase of load demand and of renewable generation scenarios.

In the load increasing scenario, the load demand is increased by $1 \%$ for each iteration for each load bus in each time step. In order to ensure proper balance and avoid power shortage, the generation capacity is incremented uniformly, of the same amount. Therefore, for each load iteration $\lambda$ the energy market in Equations (1)-(4) and the load flow problem in Equations (5)-(11) are solved with new input parameter of load demand $P D_{b}^{\lambda}(t)$ and maximum generation level $P_{g}^{\max , \lambda}$, defined as follows:

$$
\begin{aligned}
P D_{b}^{\lambda}(t)= & (1+0.01 \cdot \lambda) \cdot P_{b}^{D}(t) \forall b=1, \ldots, N_{B} \vee \forall t=1, \ldots, N_{T} \\
& P_{g}^{\max , \lambda}=(1+0.01 \cdot \lambda) \cdot P_{g}^{\max } \forall g=1, \ldots, N_{G}
\end{aligned}
$$

At each $\lambda$-th load iteration, the branch loading $B L_{l}^{\lambda}(t)$ of each $l$-th branch in each $t$-th time step is determined. If no overload is detected according to the adopted planning standard, i.e., Equation (15) is satisfied, the procedure goes on to the next iteration, otherwise the procedure stops at given iteration number $\lambda_{x}$, and the admissible demand increase in the network under study is given by:

$$
A D I_{x}=\sum_{t=1}^{N_{T}} \sum_{b=1}^{N_{B}}\left[P D_{b}^{\lambda_{x}}(t)-P D_{b}(t)\right]=0.01 \cdot \lambda_{x} \cdot \sum_{t=1}^{N_{T}} \sum_{b=1}^{N_{B}} P D_{b}(t)
$$

The load increase indicator of the $x$-th candidate project is therefore determined by difference between the result of the developed network (considering the input variation on $e_{k, x}^{\max }$ and $Y_{x}$ further than the scenario influence) and of the base case (subscript BC), as follows:

$$
I D_{x}=A D I_{x}-A D I_{B C}
$$

In the renewable increasing scenario, the power generation amount by renewablebased generation technologies is increased by $1 \%$ for each $\rho$-th iteration in each time step. In this case, no intervention on power balance is operated, i.e., load demand and conventional power generation are not varied, since the aim is to investigate the effect of a growing renewable share in the power generation mix. Therefore, for each renewable iteration $\rho$ the energy market in Equations (1)-(4) is solved with new input parameter of 
maximum generation level $P_{g}^{\max , \rho}$ applied to the $g$-th renewable generator (in the subset $\Omega_{R}$ of renewable generators, in number $N_{R}<N_{G}$ ) defined as follows:

$$
P_{g}^{\max , \rho}=(1+0.01 \cdot \rho) \cdot P_{g}^{\max } \forall g \in \Omega_{R}
$$

According to energy market results, giving different production levels for all generators $P_{g}^{\rho}(t)$ due to a new equilibrium point, the load flow analysis (5)-(11) is carried out.

At each $\rho$-th renewable iteration, the branch loading $B L_{l}^{\rho}(t)$ of each $l$-th branch in each $t$-th time step is determined. If no overload is detected according to the adopted planning standard, i.e., condition (15) is satisfied, the procedure goes on to the next iteration, otherwise the procedure stops at a given iteration number $\rho_{x}$, and the admissible renewable generation increase in the network under study is given by

$$
A R I_{x}=\sum_{t=1}^{N_{T}} \sum_{g \in \Omega_{R}}\left[P_{g}^{\rho_{x}}(t)-P_{g}(t)\right]
$$

The renewable generation increase indicator of the $x$-th candidate project is therefore determined by difference between the result of the developed network (considering the input variation on $e_{k, x}^{\max }$ and $Y_{x}$ further than the scenario influence) and of the base case (subscript $B C$ ), as follows:

$$
I R_{x}=A R I_{x}-A R I_{B C}
$$

A representation of the technical merit indicator determination process is depicted in the flowchart reported in Figure 1. It can be noted that the method involves the storage of network operation analysis under different conditions and in the presence/absence of development project, therefore a specific calculation framework is necessary in order to collect the necessary information.

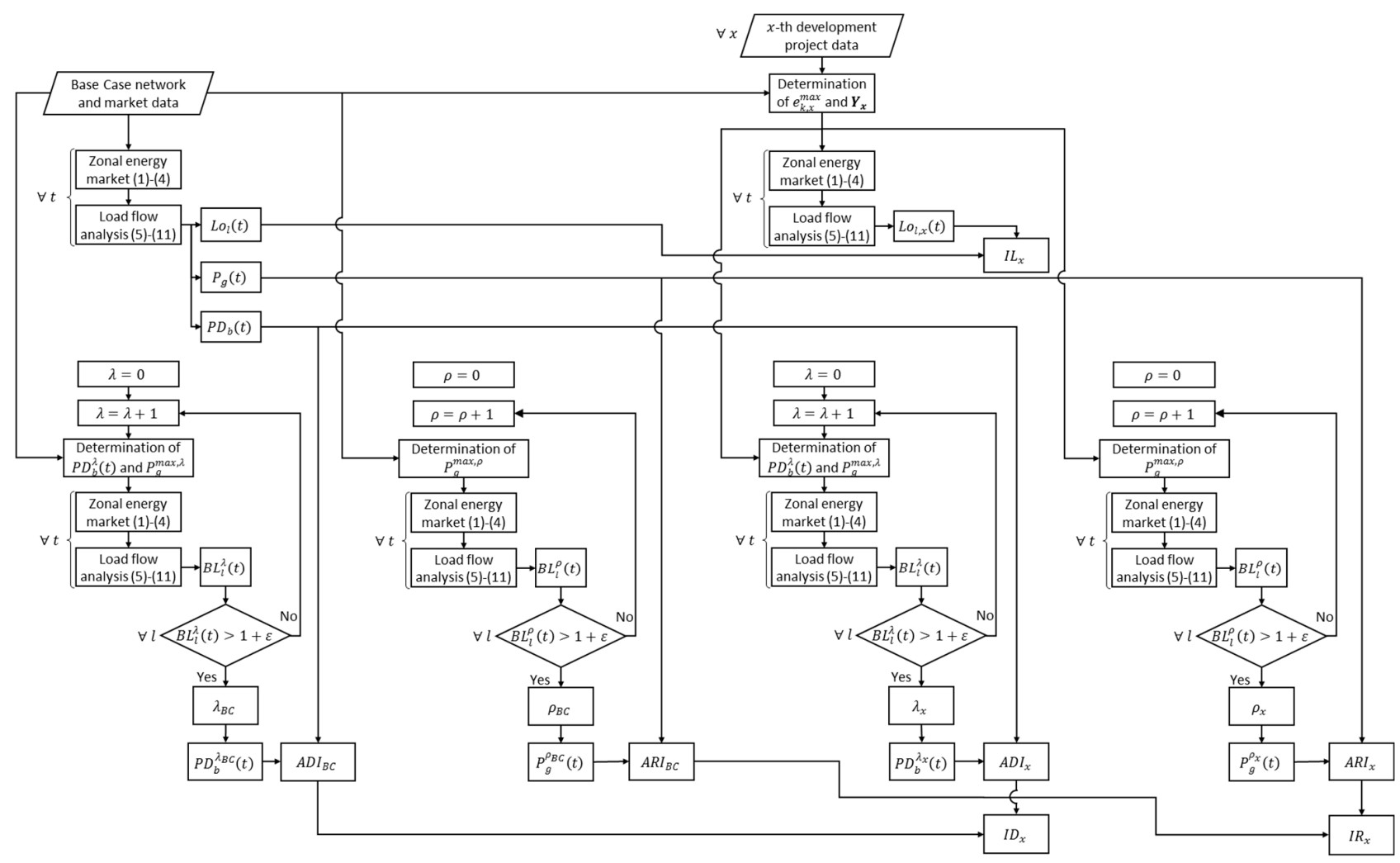

Figure 1. Flowchart representation of the determination of technical merit indicators of the $x$-th development project (right), as compared to the base case (left). 
Finally, in order to account for economic implications, an estimation of the investment cost $I C_{x}$ of the $x$-th candidate project is carried out, according to standard building and installation cost for the single components.

\subsection{Project Comparison and Selection}

As highlighted in the methodology, the three merit indicators, although referring to comparable units, measured as energy amounts over a given time horizon, are determined according to different operating conditions and evolution frameworks of the system under study. Therefore, in order to carry out a proper comparison among the outcomes of the analysis of candidate projects, Analytic Hierarchy Process (AHP) is adopted [63,64].

The AHP is based on the determination, for each $h$-th criterion evaluated for $n$ options, of the $n \times n$ pairwise comparison matrix $C^{h}$, whose element $c_{i j}^{h}$ represents the prevalence of the $i$-th option compared to the $j$-th one. If the $i$-th option is preferred to the $j$-th one, then $c_{i j}^{h}>1$, in a scale of values up to 9 according to importance comparison; for equal importance it is $c_{i j}^{h}=1$; moreover, the following reciprocal constraint applies:

$$
c_{i j}^{h} \cdot c_{j i}^{h}=1
$$

Once the matrix $C^{h}$ is built, its normalized version $C^{h N}$ by column is obtained, and its elements are determined as follows:

$$
c_{i j}^{h N}=\frac{c_{i j}^{h}}{\sum_{l=1}^{n} c_{l j}^{h}}
$$

By averaging the entries of each row of $C^{h N}$, the $n \times 1$ score vector $s^{h}$ for the $h$-th criterion is determined:

$$
s_{i}^{h}=\frac{\sum_{l=1}^{n} c_{i l}^{h N}}{n}
$$

By padding the vectors $s^{h}$ by columns, the $n \times m$ score matrix $S$ is obtained:

$$
S=\left[\begin{array}{lll}
s^{1} \ldots & s^{h} \ldots & s^{m}
\end{array}\right]
$$

Proceeding in the same way, the $m \times m$ pairwise comparison matrix $A$ of the $m$ criteria is determined whose element $a_{h f}$ represents the prevalence of the $h$-th criterion compared to the $f$-th one. Applying the same normalization and averaging process described in Equations (25) and (26), the $m \times 1$ criteria weight vector $w$ is determined.

The $n \times 1$ vector of global scores $g s$ is therefore determined by the following matrix operation, where the element $g s_{i}$ represents the global score assigned by the AHP to the $i$-th option.

$$
g s=S \cdot w
$$

For the application to the proposed framework, the $x$-th candidate project represents the generic $i$-th option, whereas the three indicators $I L_{x}, I D_{x}$ and $I R_{x}$ represent the $m$ criteria.

In addition, the consistency check is performed on pairwise comparison matrices. Taking $A$ as a reference, the consistency index is determined as follows:

$$
C I=\frac{a a-m}{m-1}
$$

where the first term $a a$ is a scalar determined as the average of the elements of the vector obtained by multiplying the rows of $A$ by $w$ and dividing by the corresponding element of $w$ :

$$
a a=\frac{1}{m} \cdot \sum_{h=1}^{m} \frac{a_{h} \cdot w}{w_{h}}
$$


The consistency ratio $C R$ is therefore determined as $C I / R I$ where the random index $R I$ is determined as the average $C I$ when elements of $A$ are random. It is considered that the consistency is acceptable if $C R<0.1$.

\section{Test System and Base Case}

\subsection{Input Data and Solution Environment}

The proposed methodology is applied to a modified version of NREL-118 test System, according to the single-line diagram shown in Figure 2, whose system data are described in [65] and thoroughly reported in [66]. A description of input data is provided in Appendix A. In particular, load and renewable generation data are provided by hours, therefore $t=1 \mathrm{~h}$ and $N_{T}=8,760$.

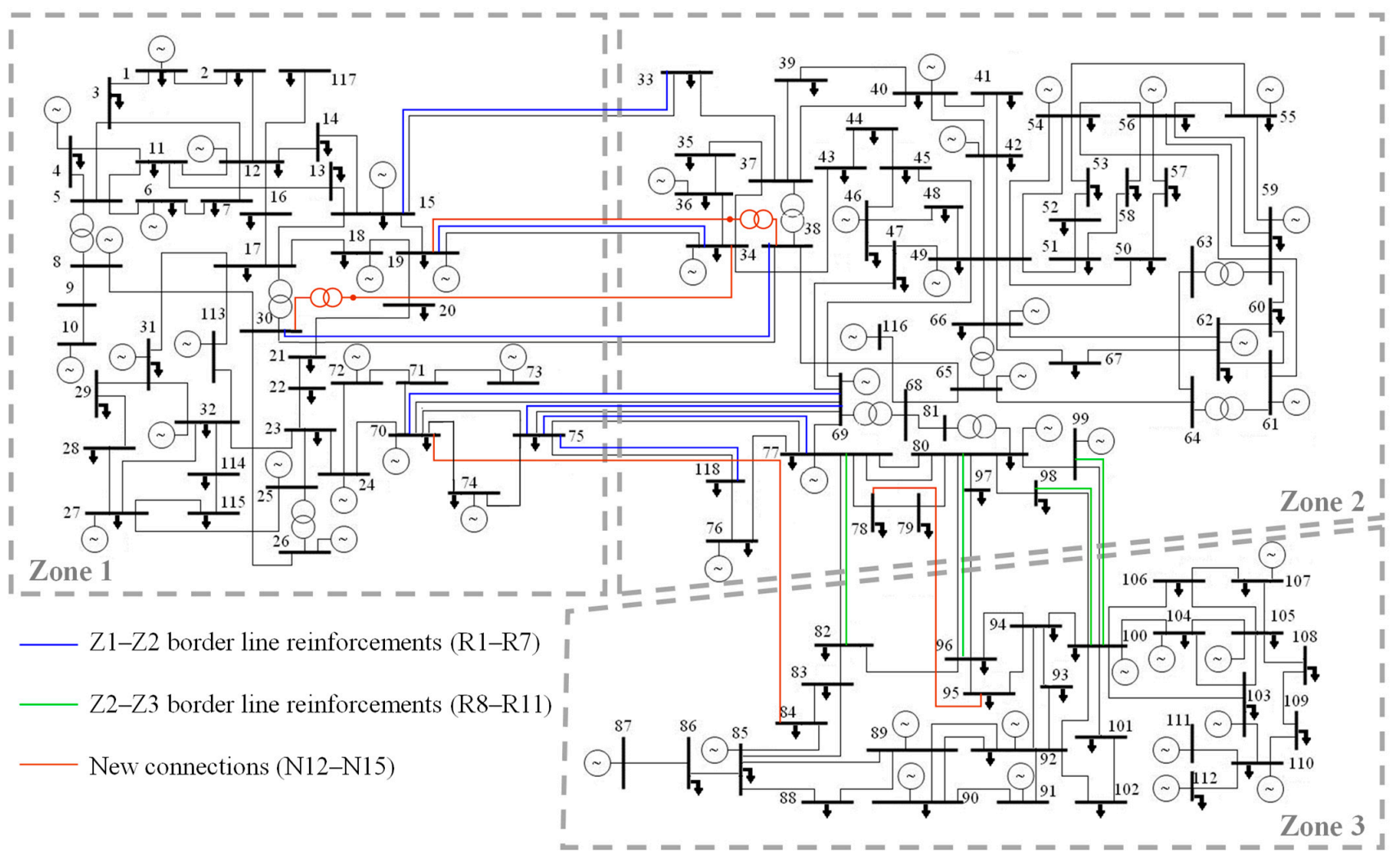

Figure 2. The NREL-118 network single-line diagram, reporting with colors the candidate projects for network reinforcements analyzed in the following.

For the scope of zonal market analysis, transfer capacities are assumed equal to the capacity of the set of connection lines; therefore, $e_{k}^{\max }$ is equal to $6400 \mathrm{MW}$ between Zones 1 and 2 and to $2500 \mathrm{MW}$ between Zones 2 and 3.

In order to carry out load flow analysis, the distributed slack is fixed at buses 25, 70, 72 and 107, hosting only conventional power plants with remarkable installed size, according to availability of the plant and to generation level margin. Moreover, it is assumed that all other 55 buses with at least one generator behave as voltage-controlled (PV) buses, considering that even photovoltaic and wind generators are more and more called to take part to voltage/reactive regulation by system operator connection standards $[67,68]$, and in these buses, voltage levels are fixed at 1.00 p.u. Moreover, according to planning standard of Italian Transmission System Operator, the margin $\varepsilon$ to evaluate a line overload considering planning viewpoint is fixed at 0.2 , i.e., no overload would be detected until the power flow level is below $120 \%$ of line rating [69,70].

The MatLAB environment is exploited to perform numeric simulations. In particular, zonal market relations are solved by building a proper optimization procedure exploiting 
quadprog function in the optimization toolbox, whereas the load flow analysis is performed by means of the MATPOWER package [71]. The determination of merit indicators exploits an iterative framework developed in MatLAB including the previously mentioned tools. It should be noted that the zonal market and load flow analysis over the yearly time horizon for a single network configuration takes roughly $3 \mathrm{~min}$ hours to be solve on an ASUS VivoBook Pro: Processor Intel i7-8750 H, CPU 2.20 GHz 6 Core(s), RAM 16 GB.

\subsection{Base Case Network Operation}

The application of energy market model (1)-(4) to the test system in the base conditions leads to the results synthesized in Figure 3 in terms of duration curve of zonal active power balance in Equation (2), where the represented values represent the power exchange of each zone. It can be seen that Zone 3 is always exporting power, having an higher generation excess in winter, and reaching in $6 \mathrm{~h}$ the power exchange limit with Zone 2 . Whereas, Zone 1 results an energy importer for most of the analyzed period, with minimum exchange of -2361.4 MW, well within Z1-Z2 boundaries, albeit it behaves as exporter for $270 \mathrm{~h}$, especially during summer, reaching maximum exchange of 1381.0 MW. Finally, Zone 2 net exchange ranges between 547.3 MW and -2075.1 MW, and net import is observed for 780 conditions.

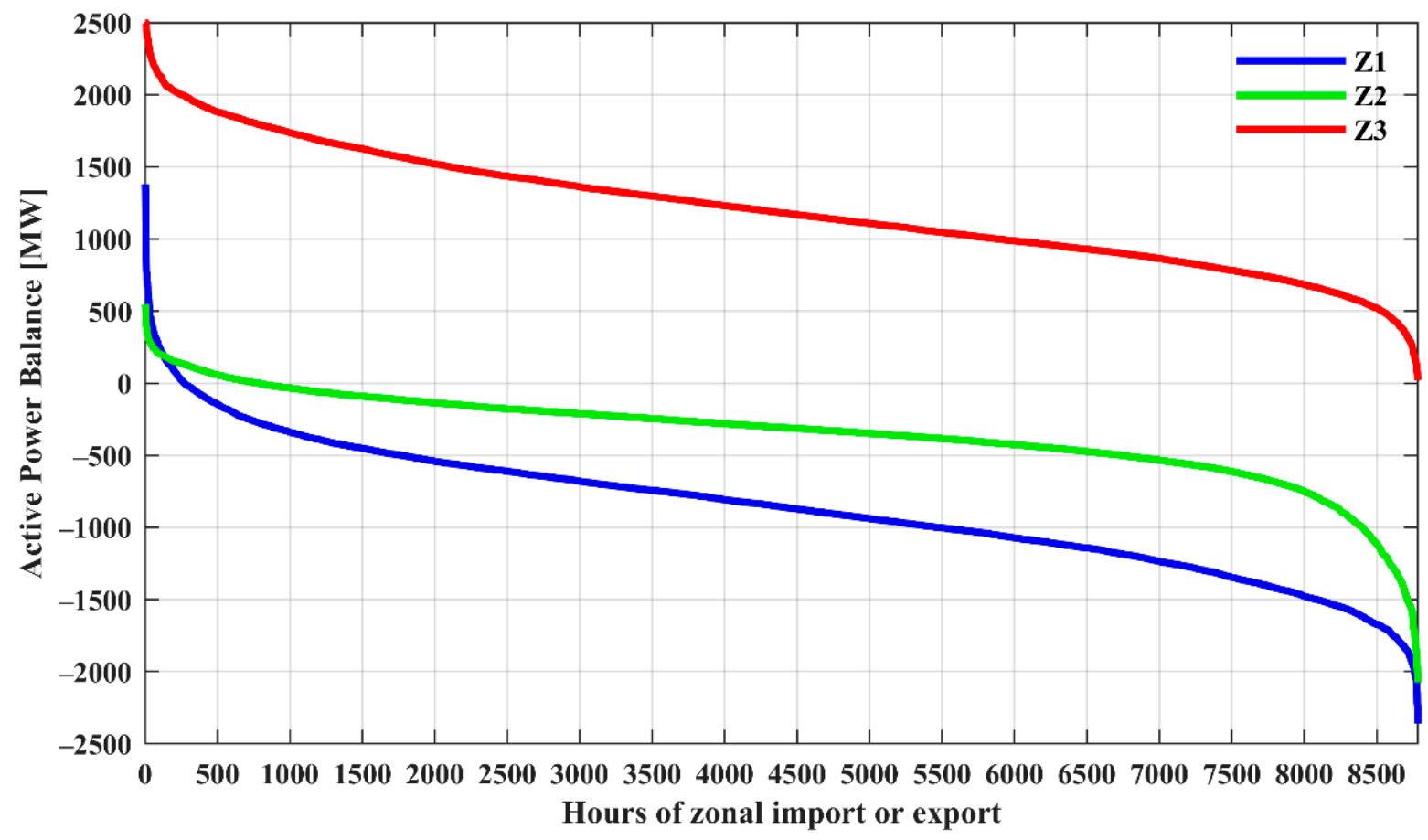

Figure 3. Duration curve of net power exchange of each zone in energy market analysis for base case network.

As regards steady-state network behaviors through relations in Equations (5)-(12) and subsequent line loading evaluation by Equations (13)-(15), the analysis of lines at zone boundaries is synthesized in Figures 4 and 5 in terms of average loading and duration curve, respectively. It can be observed that boundary lines are, on average, interested by more stressful flow levels as compared to internal lines within each zone, and lines across Z2-Z3 boundary are highly exploited, with line 99-100 reaching the maximum $B L_{l}(t)$ of $107 \%$, well within the overload limit of $120 \%$. This branch is the one on which the flow-based cost-benefit analysis methodology carried out in [41] was focused. 


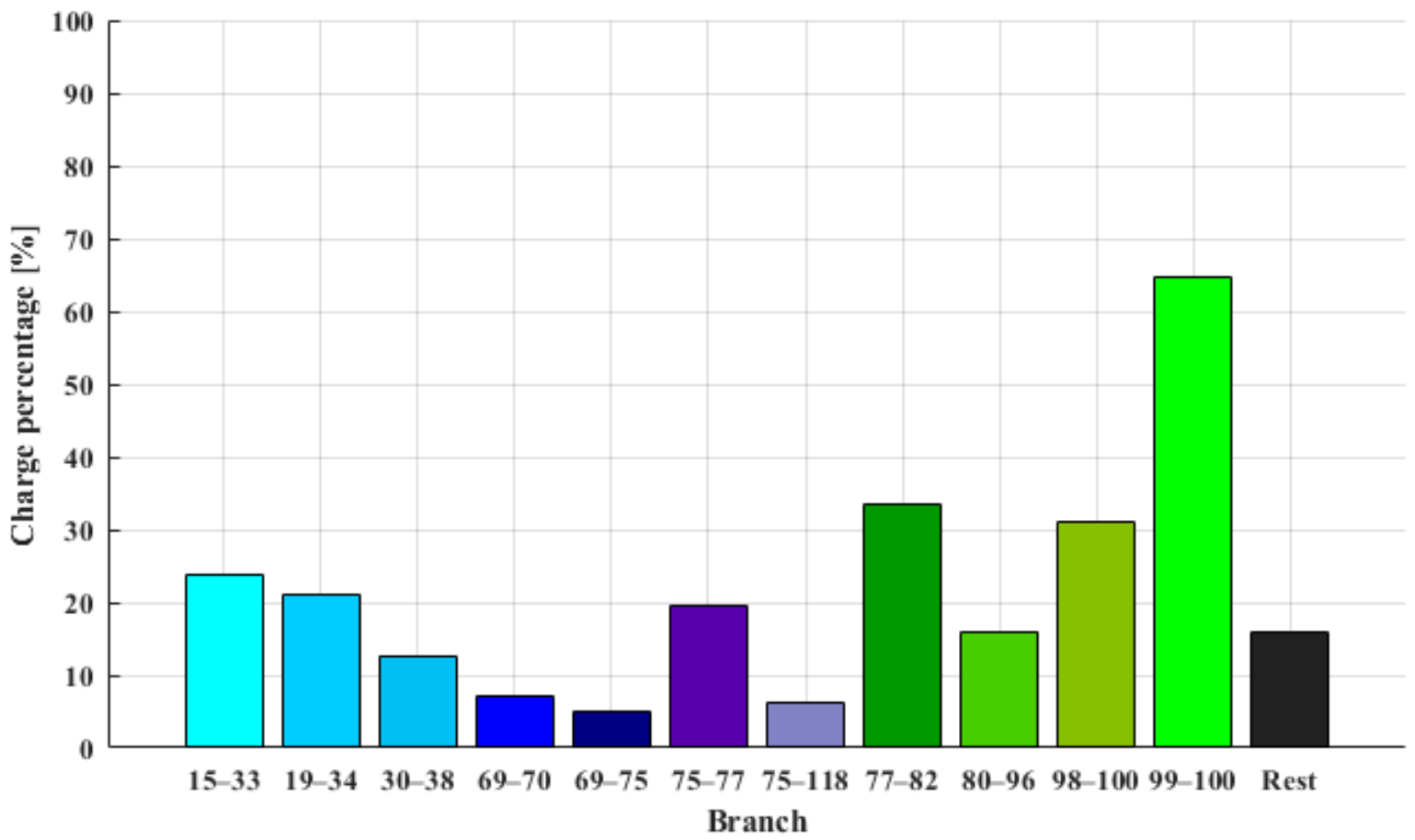

Figure 4. Yearly mean charge percentage of the candidate branches and of the hourly charge percentage mean of the other network branches.

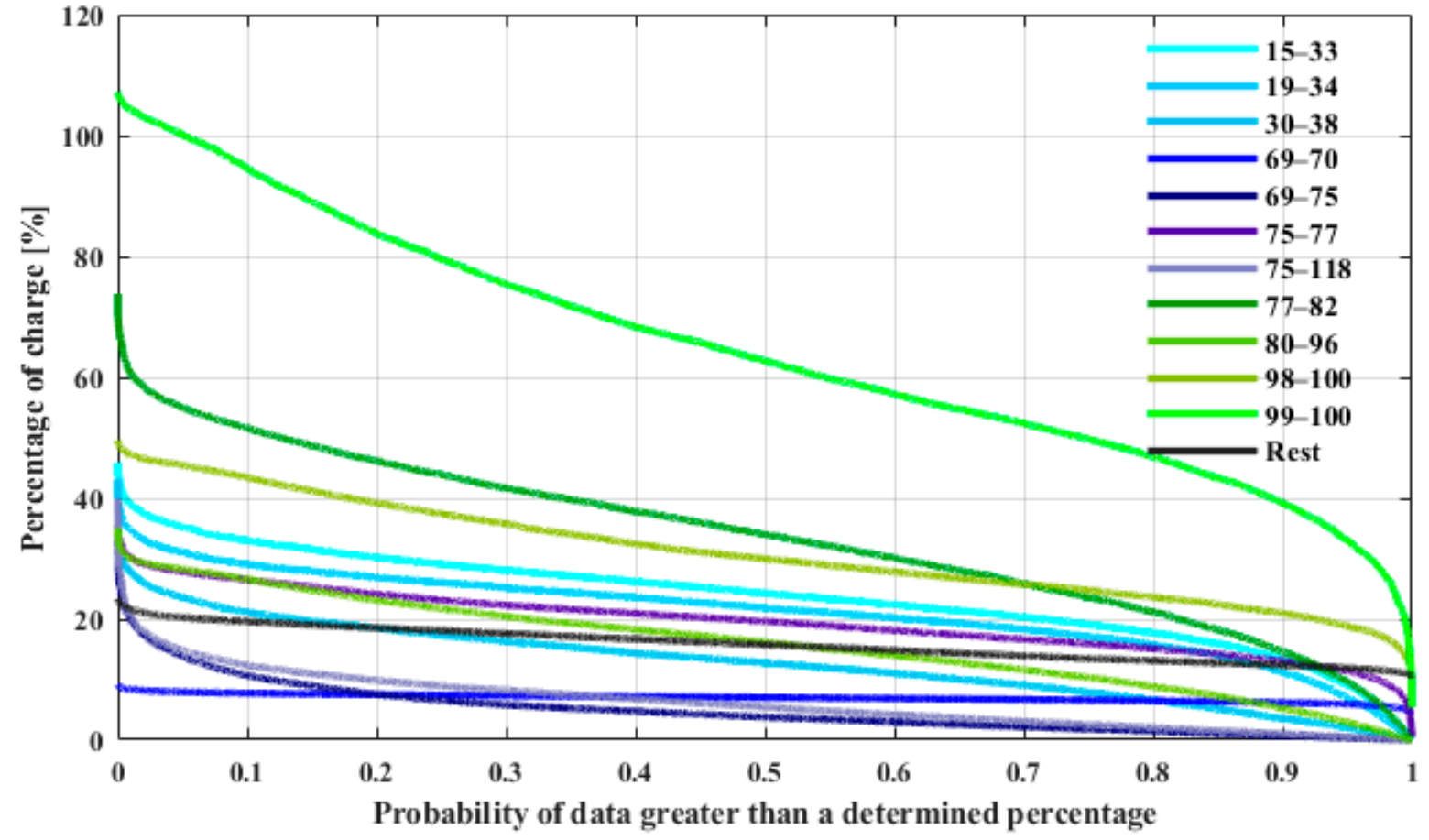

Figure 5. Percentage of charge duration curves of candidate branches and of the hourly charge percentage mean of the other network branches.

Finally, the total losses are determined, corresponding to 3,431.8 GWh, i.e., roughly $3.57 \%$ of total load demand, and in Table 1 minimum and maximum observed values of voltage magnitude $\left(V_{M}\right)$ are reported, in terms of average value over the whole time horizon for each bus and of extreme values attained in a single occurrence. It can be observed that feasible operation values are obtained, keeping in a range of $\pm 11 \%$ of nominal voltage. 
Table 1. Extreme values of average and absolute observed voltage magnitudes.

\begin{tabular}{cccc}
\hline Value & Extreme & $\boldsymbol{V}_{\boldsymbol{M}}$ [p.u.] & Bus \\
\hline \multirow{2}{*}{ average } & minimum & 0.967 & 81 \\
& maximum & 1.071 & 72 \\
\hline \multirow{2}{*}{ absolute } & minimum & 0.944 & 95 \\
& maximum & 1.109 & 107 \\
\hline
\end{tabular}

\section{Scenario Analysis and Evaluation of Indicators}

\subsection{Definition of Candidate Projects}

As explicated in the previous section, the first choice of candidate projects is devoted to the reinforcement of the existing lines across zone borders. In particular, a doubling of existing 11 border lines is considered, numbered from R1 to R11, and relevant characteristics are reported in Table 2. It can be observed that the projects have different impact on electric parameters as well as on energy market exchange level between interested zones.

Table 2. Characteristics of candidate projects of existing line reinforcements.

\begin{tabular}{|c|c|c|c|c|c|c|c|}
\hline $\begin{array}{l}\text { Candidate } \\
\text { Project id. }\end{array}$ & Nodes & $r$ [p.u.] & $x$ [p.u.] & $b$ [p.u.] & $R P_{l, x}[\mathrm{MW}]$ & Zones & $e_{k, x}^{\max }[\mathrm{MW}]$ \\
\hline R1 & $15-33$ & 0.00543 & 0.01777 & 0.22358 & +600 & $\mathrm{Z1-Z2}$ & 5600 \\
\hline $\mathrm{R} 2$ & 19-34 & 0.01074 & 0.03529 & 0.4424 & +600 & Z1-Z2 & 5300 \\
\hline $\mathrm{R} 3$ & $30-38$ & 0.00066 & 0.00771 & 2.954 & +600 & Z1-Z2 & 5300 \\
\hline $\mathrm{R} 4$ & $69-70$ & 0.00032 & 0.05879 & 0.71386 & +1700 & $\mathrm{Z} 1-\mathrm{Z} 2$ & 6400 \\
\hline $\mathrm{R} 5$ & $69-75$ & 0.00611 & 0.02014 & 0.252 & +1700 & Z1-Z2 & 6400 \\
\hline R6 & $75-77$ & 0.00441 & 0.01443 & 0.7266 & +600 & Z1-Z2 & 5300 \\
\hline R7 & 75-118 & 0.00426 & 0.01219 & 0.57218 & +600 & Z1-Z2 & 5300 \\
\hline R8 & 77-82 & 0.00509 & 0.026 & 0.3458 & +700 & Z2-Z3 & 2700 \\
\hline R9 & $80-96$ & 0.00567 & 0.02557 & 0.3332 & +600 & Z2-Z3 & 2600 \\
\hline R10 & 98-100 & 0.00257 & 0.01161 & 0.1512 & +600 & $\mathrm{Z} 2-\mathrm{Z3}$ & 2600 \\
\hline R11 & 99-100 & 0.00207 & 0.00687 & 0.08386 & +800 & $\mathrm{Z} 2-\mathrm{Z} 3$ & 2800 \\
\hline
\end{tabular}

In addition, the presence of further 4 lines creating new connection between nodes of different zones are individuated. In order to define their electric parameters, a reference path of existing lines is followed, and the relevant total impedance is reduced by a defined value in order to account for possible path savings. The features of these new connections, numbered from N12 to N15, are synthesized in Table 3. It can be noted that the projects N12 and N13 involve a transformer doubling and a new line-where path saving assumptions are applied-in order to increase the meshing of the higher voltage section across zones $\mathrm{Z1}$ and $\mathrm{Z2}$, that in the base case involves lines 8-30, 26-30, 30-38, 38-65, 65-68, 68-81. Moreover, the project N15 creates a new zonal connection between Z1 and Z3, not present in all other configurations, therefore a remarkable variation of market equilibrium is expected. Moreover, due to the bottleneck created by a single connection across zones, its contribution to market exchange level is considered equal to its rated power flow.

Table 3. Characteristics of candidate project for new line connections.

\begin{tabular}{|c|c|c|c|c|c|c|c|c|c|}
\hline $\begin{array}{l}\text { Candidate } \\
\text { Project id. }\end{array}$ & Nodes & Reference Path & $\begin{array}{l}\text { Length } \\
\text { Reduction }\end{array}$ & $r$ [p.u.] & $x$ [p.u.] & $b$ [p.u.] & $R P_{l, x}[\mathrm{MW}]$ & Zones & $e_{k, x}^{\max }[\mathrm{MW}]$ \\
\hline N12 & $19-38$ & $19-34 ; 34-37 ; 37-38$ & $30 \%$ & 0.01918 & 0.06258 & 0.09450 & +600 & Z1-Z2 & 5300 \\
\hline N13 & $30-34$ & $\begin{array}{c}30-17 ; 17-18 ; 18-19 ; \\
19-34\end{array}$ & $30 \%$ & 0.00811 & 0.03182 & 0.09450 & +600 & Z1-Z2 & 5300 \\
\hline N14 & $78-95$ & $\begin{array}{c}78-77 ; 77-82 ; 82-96 ; \\
96-95\end{array}$ & $30 \%$ & 0.01361 & 0.04882 & 0.07560 & +600 & Z2-Z3 & 2600 \\
\hline N15 & $70-84$ & $\begin{array}{c}70-75 ; 75-77 ; 77-82 ; \\
82-83 ; 83-84\end{array}$ & $30 \%$ & 0.01749 & 0.04769 & 0.32469 & +1200 & Z1-Z3 & 1200 \\
\hline
\end{tabular}


The candidate projects are represented by colored lines in the scheme reported in Figure 2.

\subsection{Evaluation of Merit Indicators for Development Projects}

As prospected in Section 2.3, the performance analysis of candidate project starts from the determination of total active power losses over the considered year of operation. The evaluation of the indicator $I L_{x}$ is reported in the second column of Table 4 , and it can be noted that the most favorable effect is attained in the presence of R11 project, giving a $2.0 \%$ reduction of total losses, whereas $\mathrm{R} 9$ project implies negligible advantage with respect to the base case.

Table 4. Results of merit indicators evaluation for the candidate projects.

\begin{tabular}{|c|c|c|c|c|c|c|c|c|}
\hline $\begin{array}{l}\text { Candidate } \\
\text { Project id. }\end{array}$ & $I L_{x}[\mathrm{MWh}]$ & $I D_{x}[\mathrm{MWh}]$ & $\lambda_{x}$ & $\begin{array}{c}\text { Limiting } \\
\text { Overload in } \\
\text { Load Increase }\end{array}$ & $I R_{x}[\mathrm{MWh}]$ & $\rho_{x}$ & $\begin{array}{c}\text { Limiting } \\
\text { Overload in } \\
\text { Renew. Increase }\end{array}$ & $I C_{x}[\mathrm{M} €]$ \\
\hline R1 & 16,305 & 1921 & 6 & $30-38$ & 13,868 & 415 & $77-82$ & 232.8 \\
\hline $\mathrm{R} 2$ & 30,936 & 3840 & 8 & $30-38$ & 13,868 & 415 & $77-82$ & 462.3 \\
\hline R3 & 39,077 & 52,814 & 59 & 99-100 & 13,868 & 415 & $77-82$ & 170.6 \\
\hline $\mathrm{R} 4$ & 39,539 & 4801 & 9 & $30-38$ & 13,868 & 415 & $77-82$ & 650.4 \\
\hline R5 & 43,054 & 3840 & 8 & $30-38$ & 13,868 & 415 & $77-82$ & 222.8 \\
\hline R6 & 52,637 & 3840 & 8 & $30-38$ & 13,014 & 395 & $77-82$ & 189.0 \\
\hline R7 & 31,207 & 3840 & 8 & $30-38$ & 13,014 & 395 & $77-82$ & 159.7 \\
\hline R8 & 9673 & 0 & 4 & $30-38$ & 15,788 & 460 & $75-77$ & 340.6 \\
\hline R9 & 98 & 0 & 4 & $30-38$ & 0 & 90 & $75-77$ & 335.0 \\
\hline R10 & 25,449 & 0 & 4 & $30-38$ & 3414 & 170 & $75-77$ & 152.1 \\
\hline R11 & 69,378 & 960 & 5 & $30-38$ & 14,079 & 420 & $75-77$ & 90.0 \\
\hline N12 & 33,644 & 1921 & 6 & $30-38$ & 13,868 & 415 & $77-82$ & 607.7 \\
\hline N13 & 8008 & 44,171 & 50 & 99-100 & 13,868 & 415 & $77-82$ & 348.8 \\
\hline N14 & 25,024 & 0 & 4 & $30-38$ & 4694 & 200 & $75-77$ & 639.6 \\
\hline N15 & 44,773 & 0 & 4 & $30-38$ & 8961 & 300 & $75-77$ & 624.8 \\
\hline
\end{tabular}

The determination of admissible load increase in the base case results in the procedure stop at iteration $\lambda_{B C}=4$, therefore only $4 \%$ of load increase (3841 GWh roughly) results admissible in the base case network configuration, being the line between nodes 30-38 the first to experience an overload. The evaluation of the indicator $I D_{x}$ is reported in the third column of Table 4, and in the fourth one the corresponding $\lambda_{x}$ is reported, whereas in the fifth the limiting overloaded line is pointed out. It can be noted that a set of projects ( $R 8$, R9, R10, N14 and N15) do not provide remarkable advancement with respect to the Base Case, and many other cases imply a further admissible increase by less than $6 \%$ of load demand, being the line 30-38 the limiting overload. In R3 and N13, intervening on line $30-38$ or in its surroundings, the load increase is higher than $45 \%$ and the limiting overload moves to line 99-100.

The determination of admissible renewable generation increase in the base case results in the procedure stop at iteration $\rho_{B C}=90$, therefore $90 \%$ of renewable generation increase (3840 GWh roughly, closely related to load increase) results admissible in the base case network configuration. In the base case, the limiting overload is observed on the line between nodes 77-82 due to the different distribution of renewable generators with respect to load. The evaluation of the indicator $I R_{x}$, of the corresponding $\rho_{x}$ and of the limiting overloaded line is illustrated in seventh, eighth and ninth columns of Table 4 . It can be seen that all the projects affecting the Z1-Z2 border overcomes 300\% of further increase, with the maximum of R8 project equal to global $460 \%$ of increase, with limiting overload between nodes 77-82 (zone Z2-Z3). Whereas, for project on Z2-Z3 border or on new Z1-Z3 connection, the limiting overload is for the line between nodes 75-77 (zones Z1-Z2) but the impact is variable, from no advantage in R9 to levels in R11, N12 and N13 comparable with those of Z1-Z2 lines. 
The estimation of investment cost $I C_{x}$ is reported in the last column of Table 4 . Analogously to [41], the estimation is based on average installation costs for overhead lines [72], considering the different voltage values and flow ratings and determining line length according to typical resistance and reactance values per unit length, whereas for high voltage self-transformers of suitable power ratings the cost estimation is taken from [73]. It can be noted that project R11 is the one with the lowest economic effort, that is considerably higher for R4, interesting a high-rating long line, for N12 due to mixed voltage level with considerable length, and for N14 and N15 due to the presence of long paths.

\subsection{Selection of Projects}

The AHP process explicated in Section 2.4 is therefore applied to the obtained merit indicators.

Since the indicators are all represented by numeric factors (all measured in GWh) in order to determine the pairwise comparison matrix $C^{h}$ of options, for each pair of candidate projects the difference between the indicators is performed, assigning preference levels from 1 to 9 according to the inclusion in intervals defined in Table 5. This method is applied only if the index of $x$-th candidate project is not lower than the index of the compared $\chi$-th project, since the reciprocal case has to comply with the constraint in Equation (24). It should be noted that for the investment cost index, the difference is inverted, since in this case the lower the better, differently from technical merit indicators.

Table 5. Thresholds for preference levels in AHP according to values of difference of index between $x$-th and $\chi$-th candidate project.

\begin{tabular}{|c|c|c|c|c|}
\hline AHP Level & $I L_{x}-I L_{\chi}$ & $I D_{x}-I D_{\chi}$ & $I R_{x}-I R_{\chi}$ & $I C_{\chi}-I C_{x}$ \\
\hline 1 & {$[0 ; 1000)$} & {$[0 ; 750)$} & {$[0 ; 200)$} & {$[0 ; 5)$} \\
\hline 2 & {$[1000 ; 3000)$} & {$[750 ; 1500)$} & {$[200 ; 1000)$} & {$[5 ; 40)$} \\
\hline 3 & {$[3000 ; 9000)$} & {$[1500 ; 3000)$} & {$[1000 ; 2500)$} & {$[40 ; 80)$} \\
\hline 4 & {$[9000 ; 18,000)$} & {$[3000 ; 5000)$} & {$[2500 ; 5000)$} & {$[80 ; 180)$} \\
\hline 5 & {$[18,000 ; 30,000)$} & {$[5000 ; 10,000)$} & {$[5000 ; 8000)$} & {$[180 ; 300)$} \\
\hline 6 & {$[30,000 ; 40,000)$} & {$[10,000 ; 40,000)$} & {$[8000 ; 11,000)$} & {$[300 ; 400)$} \\
\hline 7 & {$[40,000 ; 50,000)$} & {$[40,000 ; 49,000)$} & {$[11,000 ; 13,500)$} & {$[400 ; 450)$} \\
\hline 8 & {$[50,000 ; 60,000)$} & {$[49,000 ; 51,000)$} & {$[13,500 ; 14,000)$} & {$[450 ; 530)$} \\
\hline 9 & $\geq 60,000$ & $\geq 51,000$ & $\geq 14,000$ & $\geq 530$ \\
\hline
\end{tabular}

The outcomes of the consistency test on each matrix is therefore reported in Table 6, where the RI value of 1.58 for a $15 \times 15$ pairwise comparison matrix is exploited, as can be found in $[74,75]$, It can be seen that consistency level is acceptable for all the three indices, being $C R<0.1$ in all cases.

Table 6. Consistency analysis of the AHP matrices for each index of the candidate projects.

\begin{tabular}{|c|c|c|c|c|}
\hline & $I L_{x}-I L_{\chi}$ & $I D_{x}-I D_{\chi}$ & $I R_{x}-I R_{\chi}$ & $I C_{\chi}-I C_{x}$ \\
\hline$n$ & 15 & 15 & 15 & 15 \\
\hline$a a$ & 17.124 & 16.063 & 15.892 & 16.918 \\
\hline$C I$ & 0.1517 & 0.0759 & 0.0637 & 0.137 \\
\hline$R I$ & 1.58 & 1.58 & 1.58 & 1.58 \\
\hline$C R$ & 0.096 & 0.0481 & 0.0403 & 0.0867 \\
\hline
\end{tabular}

The corresponding values of the score matrix $S$ are graphically represented in Figure 6 . It can be observed that, as expectable, candidate projects R11, R6 and N15 show good performances for losses, projects R3, N13 and R4 for demand increase, projects R8 and R11 for renewable increase, and projects R11, R10 and R7 for economic effort. Moreover, by posing a selection threshold of $1 / 15=0.06667$, that would be the value of scoring if all project had the same importance, it can be seen that a number of $6,3,9$ and 7 projects would pass the threshold for the four criteria, respectively. It can be further observed that 
R3 passes the threshold in all four indicators, whereas R5 and R11 in three out of four, and $\mathrm{R} 9$ and N14 do not show positive performance in all four analyzed aspects.

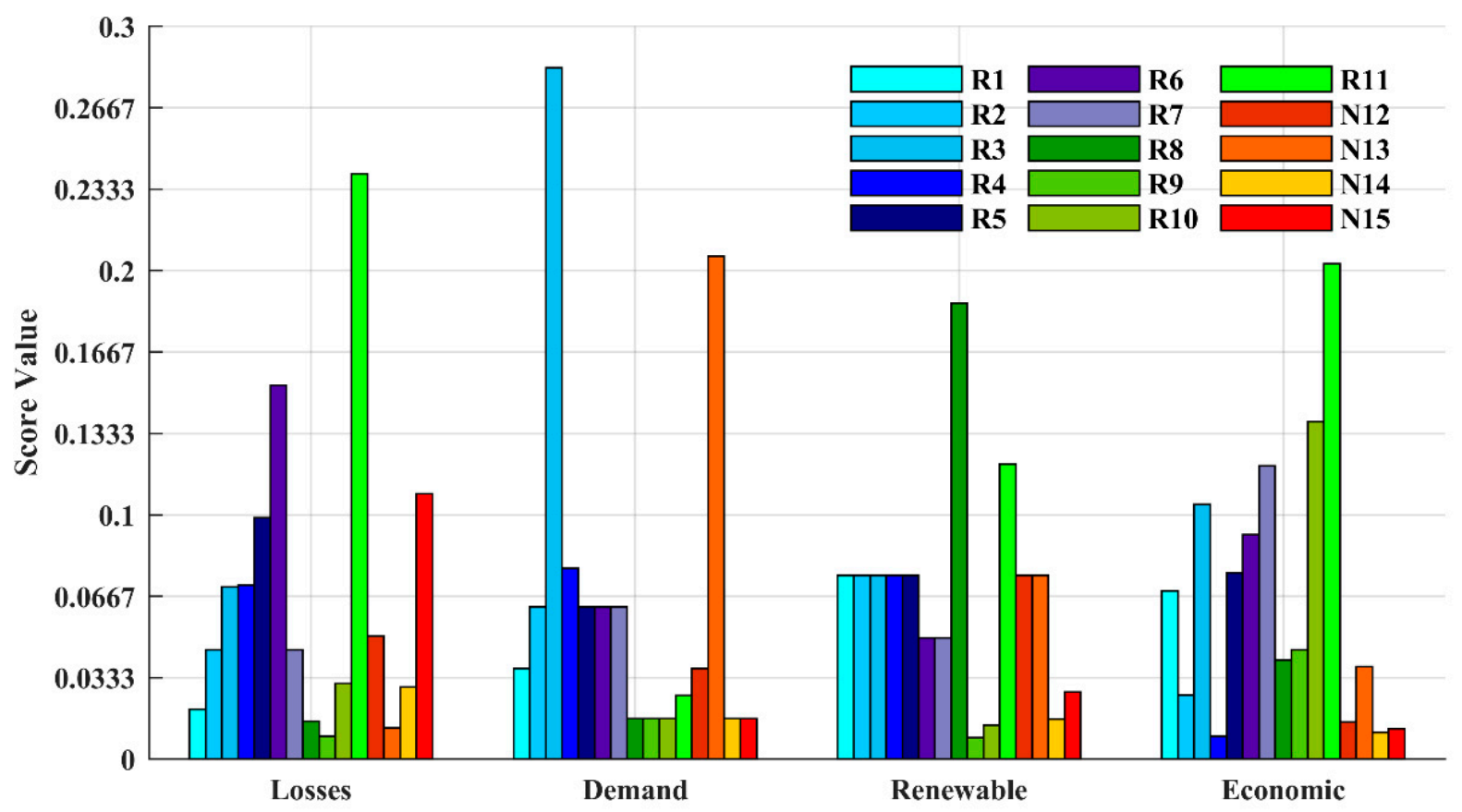

Figure 6. Graphical representation of score values by column (criteria).

\subsubsection{Cases Based on Technical Indicators}

In order to determine the criteria weight vector $w$, a set of different hypotheses has been applied, thus obtaining different estimations. A first assumption is that of equal importance for the three technical indices (Case EIT), giving a vector of equal weight values of $1 / 3$. Therefore, a "slightly more importance" level is assigned to one index per time, thus considering $a_{h f}=3$ for the selected index $h$, with the aim to investigate the validity of the prevalence of one criterion to the others (Cases LD-losses dominance, DDdemand dominance, $\mathrm{RD}$-renewable dominance). Moreover, assuming the viewpoint of a power system planner aiming at facing the challenges of energetic evolution given by the integration of increasing greener generation with an additional insight to power demand, a dominance level 3 is assigned to renewable increase with respect to losses, and a dominance level 2 is assigned to renewable with respect to demand and to demand with respect to losses (Case PVP, planning viewpoint). These considerations lead to five cases of criteria weight vector $w$, with values reported in Table 7 . It is easy to verify that each of the considered cases has a perfect consistency of pairwise comparison, since $C I=0$.

Table 7. Criteria weight vectors in the five considered cases.

\begin{tabular}{|c|c|c|c|c|c|}
\hline Criterion $\quad$ Case & EIT & LD & DD & RD & PVP \\
\hline Losses & 0.33333 & 0.6 & 0.2 & 0.2 & 0.16378 \\
\hline Demand & 0.33333 & 0.2 & 0.6 & 0.2 & 0.29726 \\
\hline Renewable & 0.33333 & 0.2 & 0.2 & 0.6 & 0.53896 \\
\hline
\end{tabular}

The vectors of global scores obtained in the five prospected cases are depicted in Figure 7. It can be noted that in each case 7 projects pass the selection threshold, with the exception of DD with 6 cases, however the results are different. In EI and DD Cases, R3 is the preferable solution, whereas in LD and DD cases the best compromise is represented by R11, that is the project examined in [41] in the cost-benefit analysis framework. In PVP Case, 
representing the reference for the power system planning, the rank of suitable candidate project over the threshold is R3, R11, R8, N13, R4, R5, R6. It can be argued that, under the considered assumptions, there is more value in reinforcement projects than in paving new connections, and the different weighting assumptions, representing contrasting evolution viewpoints, can affect the ranking given the numerical outcomes of the techno-economic analysis and index determination.

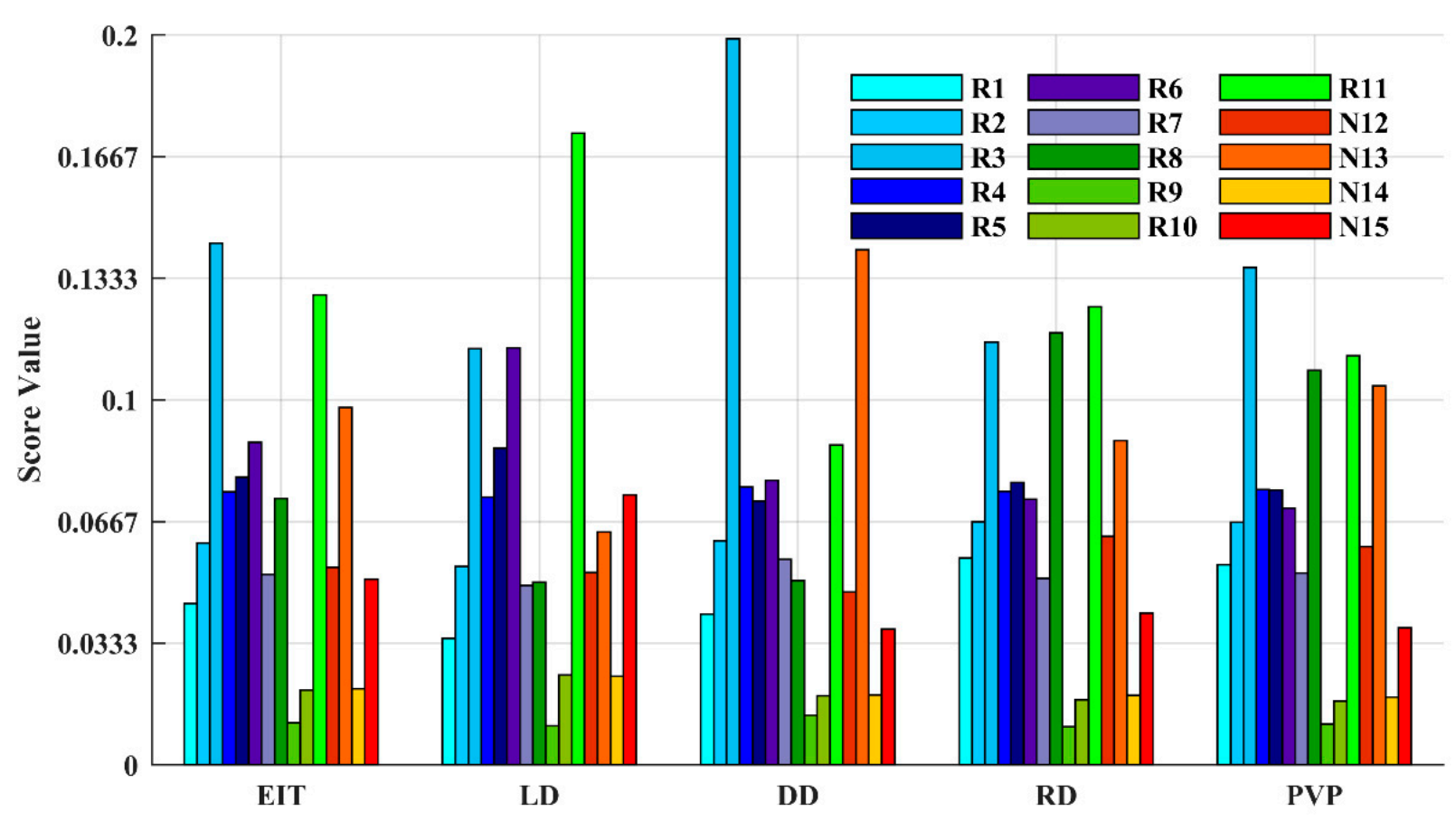

Figure 7. Values of global scores $g s$ in the five considered cases.

\subsubsection{Influence of Economic Effort}

In order to assess the influence of investment cost in project selection, a further analysis is carried out including the economic effort scores in the AHP. Three further scenarios are therefore analyzed. In the levelized weighting case (Case LW), the four merit indicators assume the same importance, therefore all the elements of the vector of weight values is $1 / 4$. The economic effort dominance (EED) is assessed by imposing a dominance level 5 to economic effort criterion on the three technical indicators, therefore expressing a strong preference to investment reduction. Finally, the viewpoint of a power system planner is represented by Techno-Economic Planner Perspective (TEPP), where a dominance level 4 is assigned to renewable and economic effort with respect to losses, a dominance level 3 is assigned to demand w.r.t. to losses and to economic effort w.r.t. to demand, and a dominance level 2 is assigned to renewable w.r.t. to demand and to economic effort w.r.t. renewable. These considerations lead to three further formulations of criteria weight vector $w$, with values reported in Table 8. It is easy to verify that each of the considered cases has a perfect consistency of pairwise comparison, since $C I=0$, except for the TEPP where $C I=0.051$.

Table 8. Criteria weight vectors in the three techno-economic cases.

\begin{tabular}{ccccc}
\hline Criterion & Case & LW & EED & \multirow{2}{*}{ TEPP } \\
\hline Losses & 0.25 & 0.125 & 0.08066 \\
Demand & 0.25 & 0.125 & 0.17531 \\
Renewable & 0.25 & 0.125 & 0.28895 \\
Economic effort & 0.25 & 0.625 & 0.45509 \\
\hline
\end{tabular}


The vectors of global scores obtained in the three techno-economic prospected cases are represented in Figure 8. It can be seen that in LW and EED cases, as compared to the EIT Case in Section 4.3.1, the presence of investment cost makes the interest to R7 and R10 increase, due to their cheaper economic effort, to the detriment of R4 and N13. In the TEPP case, 8 projects pass the threshold, i.e., R11, R3, R7, R6, R8, N13, R5 and R10, and the comparison with PVP shows that the economic effort does not remarkably affect the leading projects of the obtained ranking, although further limiting the appeal of more challenging projects (e.g., new long connections or high-rating projects or multi-voltage levels).

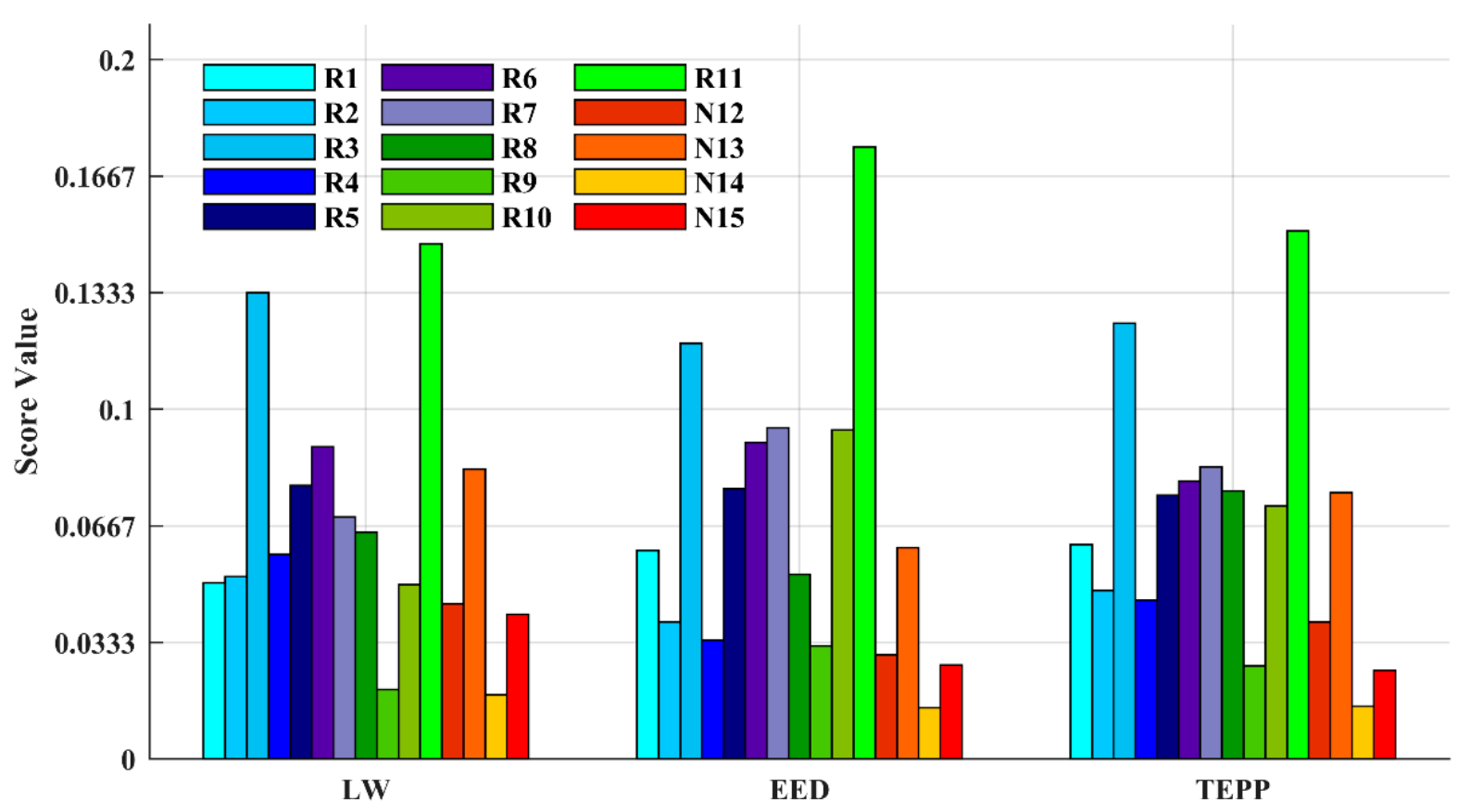

Figure 8. Values of global scores $g s$ in the three techno-economic considered cases.

\section{Conclusions}

In this paper, a methodology for the determination of network development candidate projects and for the evaluation of relevant performance indicators has been carried out. In the framework of energy sector unbundling, the methodology has involved zonal market solution by means of a quadratic optimization and steady-state network analysis, applied over a defined time horizon, leading to the determination of candidate project from the base case. These development projects have been evaluated by means of the same tools, in order to calculate technical merit indicators on active power losses, admissible load increase and admissible renewable generation increase. In order to perform a comparison of heterogeneous aspects, the outcomes of candidate project study have been analyzed through an Analytic Hierarchy Process method, considering different weighting methods for technical criteria. In addition, the influence of economic effort for project is assessed by including investment cost estimation as a further criterion in AHP method and comparing the classification list of projects under different assumptions. Procedure application to NREL-118 test system over a yearly operation window has shown the validity of the approach, given that the assessed critical expansion projects are analogous to other methods based on TEP optimization or flow-based approaches. Moreover, the indicator comparison through AHP revealed a synthetic though powerful tool to put heterogeneous aspects in a common framework, where evolution scenarios can be efficiently represented by weighting criteria of indicators, prioritizing the attention of the system operator to a subset of projects where a specific cost-benefit analysis could be applied. The procedure has proved flexible enough to envisage its application to real-scale transmission network analysis, where the analytic TEP methods could reveal hard to apply and the operation experience can 
lead to further selection of projects, and the increased numerical complexity could be efficiently dealt with by AHP. In a future work, additional CBA and N-1 security criteria could be assessed for the most profitable projects to reduce computational costs concerning network extension.

Author Contributions: Conceptualization, M.D. and G.F.; methodology, M.D., G.F. and G.T.; software, G.T.; formal analysis, G.F. and F.M.; investigation, G.T. and F.M.; data curation, G.F. and G.T.; writing—original draft preparation, G.F. and G.T.; writing—review and editing, M.D.; visualization, G.T. and F.M.; supervision, M.D. All authors have read and agreed to the published version of the manuscript.

Funding: This research received no external funding.

Institutional Review Board Statement: Not applicable.

Informed Consent Statement: Not applicable.

Data Availability Statement: Not applicable.

Acknowledgments: Not applicable.

Conflicts of Interest: The authors declare no conflict of interest.

\section{Appendix A. Test System Features}

The modified version of NREL 118-Bus system presents a total installed production capacity of $40.5 \mathrm{GW}$, subdivided among the three zones as reported in Table A1. The installed generation capacity in the Zones 1, 2 and 3 are equal to $26.0 \%, 48.6 \%$ and $25.5 \%$ respectively. Roughly $42.5 \%$ of installed generation capacity is based on thermoelectric generation (combined cycles - CC, combustion turbines-CT, steam turbine-ST and internal combustion engines-ICE), and more than half of it is present in Zone 1. Moreover, 21.3\% is covered by programmable renewables-mainly hydroelectric in Zone 2-and $36.2 \%$ is represented by photovoltaic, wind and non-dispatchable hydroelectric, with higher share of Zone 3.

Minimum and maximum bid prices for fuel-based plants (thermoelectric and biomass) are reported in Table A2, gathered by technology. It can be seen that most of gas-based production has a production cost lower than $30 \$ / \mathrm{MWh}$, comparable with biomass, whereas oil-based technology is the less competitive.

Table A1. Zonal installed capacity by technology [MW].

\begin{tabular}{ccccc}
\hline Technology & Zone $\mathbf{1}$ & Zone $\mathbf{2}$ & Zone 3 & Total \\
\hline CC gas & 5812.1 & 1743.9 & 3436.1 & $10,992.1$ \\
CT gas & 1356.3 & 374.5 & 1549.3 & 3280.1 \\
CT oil & 223.5 & 142.4 & 0 & 365.9 \\
ICE gas & 0 & 50.4 & 3.3 & 53.7 \\
ST coal & 20.0 & 0 & 0 & 20.0 \\
ST gas & 1482.2 & 0 & 978.4 & 2460.6 \\
ST other & 35.0 & 0 & 0 & 35.0 \\
Biomass & 58.2 & 16.5 & 40.2 & 114.9 \\
Geothermal & 0 & 22.0 & 0 & 22.0 \\
Hydro prog. & 0 & 8383.6 & 110 & 8493.6 \\
Hydro non-disp. & 0.8 & 8506.4 & 1649.5 & $10,156.7$ \\
Wind & 329.0 & 0 & 749.0 & 1078.0 \\
Photovoltaic & 1206.0 & 444.4 & 1795.4 & 3445.8 \\
Total & $10,523.0$ & $19,684.0$ & $10,311.1$ & $40,518.1$ \\
\hline
\end{tabular}

Total yearly demand sums up to $95.95 \mathrm{TWh}$, whereas the load value ranges from minimum 7.23 GW to maximum 17.29 GW. Load distribution among zones shows that Zone 1 has the highest share, between $43.3 \%$ and $63.5 \%$, with higher values in winter and lower in summer, whereas Zone 2 and Zone 3 have $13.4 \div 30.6 \%$ and $19.4 \div 33.9 \%$ of load 
respectively. In Figure A1 a representation of load trend for the days with lowest and highest total load level is reported.

Table A2. Generation bid price range [\$/MWh].

\begin{tabular}{ccc}
\hline Technology & Minimum & Maximum \\
\hline CC gas & $12.94 \div 28.11$ & $27.80 \div 66.34$ \\
CT gas & $15.02 \div 28.31$ & $30.22 \div 71.49$ \\
CT oil & $104.72 \div 109.32$ & $257.97 \div 264.32$ \\
ICE gas & $21.26 \div 21.39$ & $42.52 \div 42.78$ \\
ST coal & 9.15 & 20.72 \\
ST gas & $11.56 \div 26.48$ & $23.12 \div 64.98$ \\
ST other & $15.11 \div 124.10$ & $30.22 \div 290.11$ \\
Biomass & $12.47 \div 16.62$ & $28.45 \div 33.24$ \\
\hline
\end{tabular}
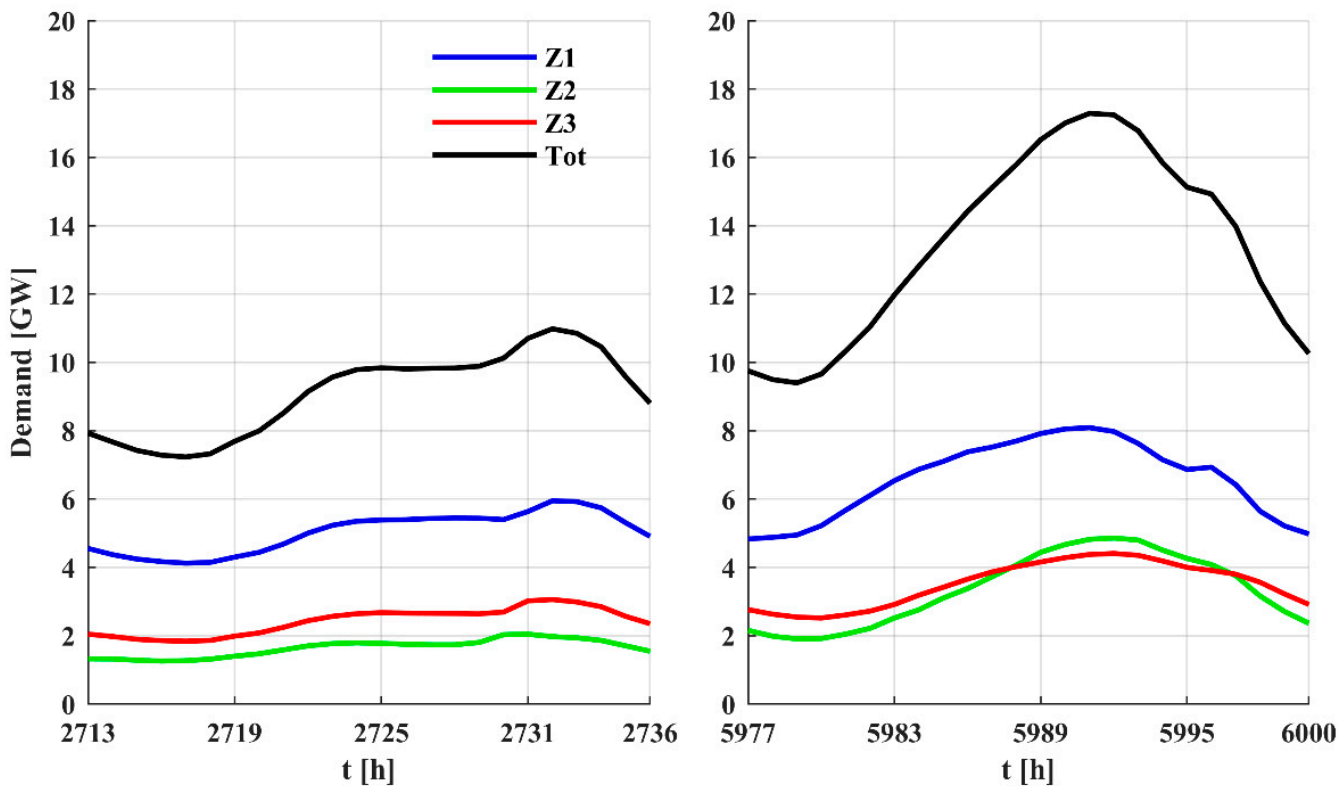

Figure A1. Trends of zonal demand in lowest load day 113 and highest load day 249.

The subdivision of load demand among buses is determined according to fixed ratio provided in [66] not reported for purpose of brevity. For the same reason, the network data for load flow analysis can be found in the database [66].

As regards non-dispatchable renewable generation, the contribution reported in [66] amounts to 2700 TWh, 7698 TWh and 2564 TWh for wind, solar and non-dispatchable hydro, respectively. Correspondently, equivalent yearly duration of $2505 \mathrm{~h}, 2234 \mathrm{~h}$ and $253 \mathrm{~h}$ for wind, solar and non-dispatchable hydro, respectively is considered. The yearly duration curves are reported in Figure A2, where it can be seen that wind and hydro show a smooth variation over time, and they do not reach null contribution in any condition, whereas solar power is working for half of total hours, as expectable. A distinction of seasonal behavior for each technology is reported in Table A3 in terms of statistical distribution quantities, where it can be noted that in summer all the three sources give the most remarkable energy contribution, although peaks are reached in spring (wind and photovoltaic) and in autumn (hydro non dispatchable). 


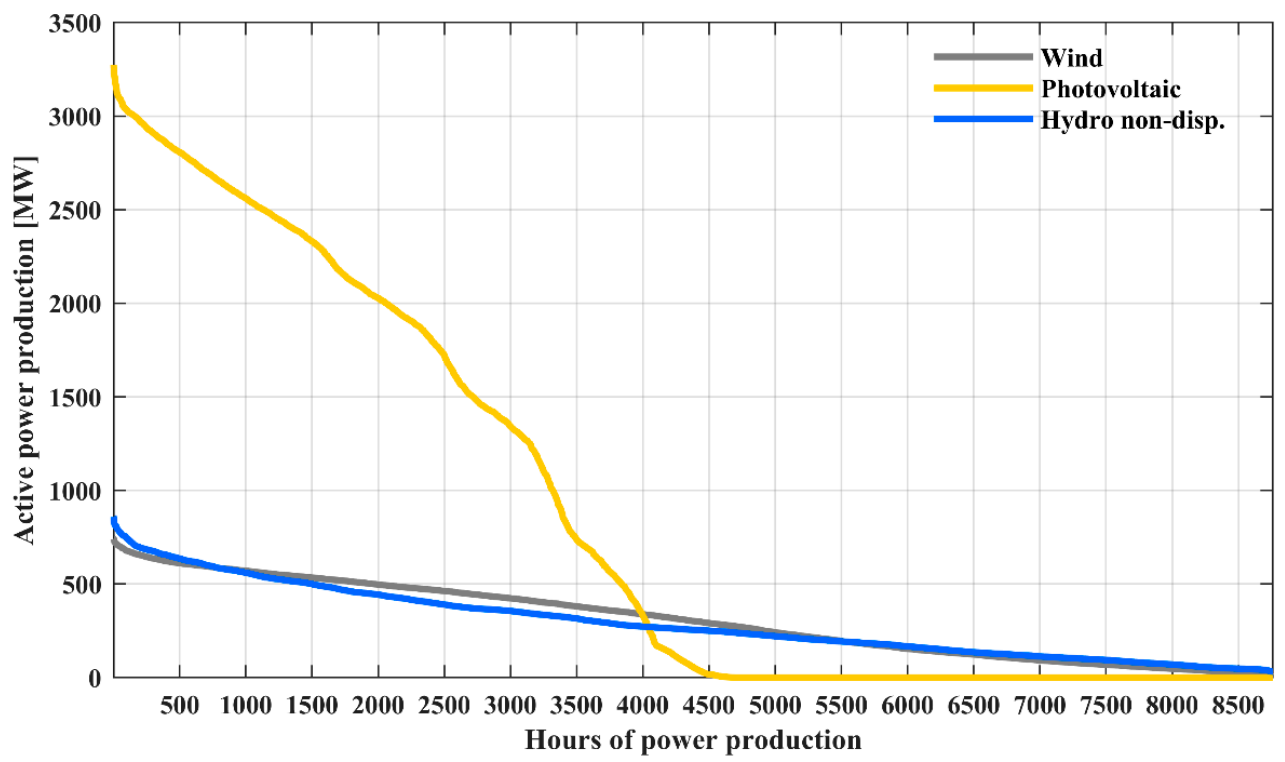

Figure A2. Duration curves of non-dispatchable renewable production.

Table A3. Characterization of seasonal behavior.

\begin{tabular}{|c|c|c|c|c|c|c|c|c|c|c|c|c|}
\hline \multirow{2}{*}{$\begin{array}{c}\text { Technology } \\
\text { Season }\end{array}$} & \multicolumn{4}{|c|}{ Wind } & \multicolumn{4}{|c|}{ Photovoltaic } & \multicolumn{4}{|c|}{ Hydro Non Disp. } \\
\hline & Winter & Spring & Summer & Autumn & Winter & Spring & Summer & Autumn & Winter & Spring & Summer & Autumn \\
\hline Minimum [MW] & 6.43 & 11.38 & 26.08 & 6.53 & 0 & 0 & 0 & 0 & 31.45 & 52.16 & 69.04 & 44.34 \\
\hline 1st quartile [ & 65.90 & 229.64 & 268.32 & 69.89 & 0 & 0 & 0 & 0 & 85.93 & 196.79 & 254.73 & 84.91 \\
\hline Median [MW] & 149.58 & 438.04 & & 168.65 & 0 & 139.62 & 303.02 & 1.60 & 119.49 & 269.29 & 426.03 & 247.12 \\
\hline Mean [MW] & 212.94 & 393.04 & 397.84 & 226.15 & 737.34 & 939.08 & 1025.44 & 809.26 & 173.79 & 301.57 & 423.56 & 269.06 \\
\hline 3rd quartile [MW] & 343.91 & 547.43 & 540.89 & 384.92 & 1645.42 & 1997.54 & 2157.63 & 1792.63 & 243.41 & 383.35 & 577.49 & 398.56 \\
\hline Maximum [MW] & 714.78 & 741.8 & 724.8 & 688.15 & 3082.08 & 3273.21 & 3125.05 & 3089.98 & 718.26 & 769.04 & 841.53 & 858.83 \\
\hline Total energy [TWh] & 0.46 & 0.87 & 0.88 & 0.49 & 1.59 & 2.07 & 2.26 & 1.77 & 0.38 & 0.67 & 0.94 & 0.59 \\
\hline
\end{tabular}

\section{References}

1. Sharan, I.; Balasubramanian, R. Integrated generation and transmission expansion planning including power and fuel transportation constraints. Energy Policy 2012, 43, 275-284. [CrossRef]

2. Munoz, F.D.; Hobbs, B.F.; Watson, J.P. New bounding and decomposition approaches for MILP investment problems: Multi-area transmission and generation planning under policy constraints. Eur. J. Oper. Res. 2015, 248, 888-898. [CrossRef]

3. Aghaei, J.; Amjady, N.; Baharvandi, A.; Akbari, M.A. Generation and transmission expansion planning: MILP-based probabilistic model. IEEE Trans. Power Syst. 2014, 29, 1592-1601. [CrossRef]

4. Gupta, N.; Khosravy, M.; Patel, N.; Senjyu, T. A bi-level evolutionary optimization for coordinated transmission expansion planning. IEEE Access 2018, 6, 48455-48477. [CrossRef]

5. Sepasian, M.S.; Seifi, H.; Foroud, A.A.; Hatami, A.R. A multiyear security constrained hybrid generation-transmission expansion planning algorithm including fuel supply costs. IEEE Trans. Power Syst. 2009, 24, 1609-1618. [CrossRef]

6. Yin, S.; Wang, J. Generation and transmission expansion planning towards a 100\% renewable future. IEEE Trans. Power Syst. 2020. [CrossRef]

7. Burgholzer, B.; Auer, H. Cost/benefit analysis of transmission grid expansion to enable further integration of renewable electricity generation in Austria. Renew. Energy 2016, 97, 189-196. [CrossRef]

8. Kemfert, C.; Kunz, F.; Rosellón, J. A welfare analysis of electricity transmission planning in Germany. Energy Policy 2016, 94, 446-452. [CrossRef]

9. Ploussard, Q.; Olmos, L.; Ramos, A. An operational state aggregation technique for transmission expansion planning based on line benefits. IEEE Trans. Power Syst. 2016, 32, 2744-2755. [CrossRef]

10. Wu, Z.; Du, X.; Gu, W.; Zhang, X.P.; Li, J. Automatic selection method for candidate lines in transmission expansion planning. IEEE Access 2018, 6, 11605-11613. [CrossRef]

11. Mehrtash, M.; Kargarian, A.; Rahmani, M. Security-constrained transmission expansion planning using linear sensitivity factors. IET Gener. Transm. Distrib. 2019, 14, 200-210. [CrossRef]

12. Freitas, P.F.; Macedo, L.H.; Romero, R. A strategy for transmission network expansion planning considering multiple generation scenarios. Electr. Power Syst. Res. 2019, 172, 22-31. [CrossRef] 
13. Sun, M.; Teng, F.; Konstantelos, I.; Strbac, G. An objective-based scenario selection method for transmission network expansion planning with multivariate stochasticity in load and renewable energy sources. Energy 2018, 145, 871-885. [CrossRef]

14. Zhuo, Z.; Du, E.; Zhang, N.; Kang, C.; Xia, Q.; Wang, Z. Incorporating massive scenarios in transmission expansion planning with high renewable energy penetration. IEEE Trans. Power Syst. 2019, 35, 1061-1074. [CrossRef]

15. Sima, C.A.; Lazaroiu, G.C.; Dumbrava, V. Transmission expansion planning optimization for improving RES integration on electricity market. In Proceedings of the 10th International Symposium on Advanced Topics in Electrical Engineering (ATEE), Bucharest, Romania, 23-25 March 2017.

16. Franken, M.; Barrios, H.; Schrief, A.B.; Moser, A. Transmission expansion planning via power flow controlling technologies. IET Gener. Transm. Distrib. 2020, 14, 3530-3538. [CrossRef]

17. Franken, M.; Schrief, A.B.; Barrios, H.; Puffer, R.; Moser, A. Co-optimization of multi-stage transmission expansion planning and grid operation. Electr. Power Syst. Res. 2020, 189, 106686. [CrossRef]

18. García-Bertrand, R.; Mínguez, R. Dynamic robust transmission expansion planning. IEEE Trans. Power Syst. 2016, 32, 2618-2628. [CrossRef]

19. Dehghan, S.; Amjady, N.; Conejo, A.J. Adaptive robust transmission expansion planning using linear decision rules. IEEE Trans. Power Syst. 2017, 32, 4024-4034. [CrossRef]

20. Zhang, X.; Conejo, A.J. Candidate line selection for transmission expansion planning considering long-and short-term uncertainty. Int. J. Electr. Power Energy Syst. 2018, 100, 320-330. [CrossRef]

21. Dehghan, S.; Amjady, N.; Conejo, A.J. A multistage robust transmission expansion planning model based on mixed binary linear decision rules-Part I. IEEE Trans. Power Syst. 2018, 33, 5341-5350. [CrossRef]

22. Huppmann, D.; Egerer, J. National-strategic investment in European power transmission capacity. Eur. J. Oper. Res. 2015, 247, 191-203. [CrossRef]

23. Lumbreras, S.; Ramos, A.; Banez-Chicharro, F.; Olmos, L.; Panciatici, P.; Pache, C.; Maeght, J. Large-scale transmission expansion planning: From zonal results to a nodal expansion plan. IET Gener. Transm. Distrib. 2017, 11, 2778-2786. [CrossRef]

24. Rathore, C.; Thote, P.B.; Kamble, S.; Naik, V.; Singh, P.; Jukaria, M. Transmission network expansion planning considering transmission switching and pumped-storage. In Proceedings of the 2017 IEEE International WIE Conference on Electrical and Computer Engineering (WIECON-ECE), Dehraun, India, 18-19 December 2017.

25. Mortaz, E.; Valenzuela, J. Evaluating the impact of renewable generation on transmission expansion planning. Electr. Power Syst. Res. 2019, 169, 35-44. [CrossRef]

26. Du, H.; Lin, T.; Bi, R.; Chen, Y.; Li, S.; Xu, X.; Liu, L. A decision support system for transmission expansion planning considering vulnerability. In Proceedings of the 2019 IEEE Power \& Energy Society General Meeting (PESGM), Atlanta, GA, USA, 4-8 August 2019.

27. Sri, M.D.; Kumari, M.V. Transmission expansion planning using differential evolution multi-objective differential evolution and multi-criteria decision making methods. In Proceedings of the 2018 National Power Engineering Conference (NPEC), Madurai, India, 9-10 March 2018.

28. El-Bages, M.S.; Elsayed, W.T. Social spider algorithm for solving the transmission expansion planning problem. Electr. Power Syst. Res. 2017, 143, 235-243. [CrossRef]

29. Da Silva, A.M.L.; Freire, M.R.; Honório, L.M. Transmission expansion planning optimization by adaptive multi-operator evolutionary algorithms. Electr. Power Syst. Res. 2016, 133, 173-181. [CrossRef]

30. Ghaddar, B.; Jabr, R.A. Power transmission network expansion planning: A semidefinite programming branch-and-bound approach. Eur. J. Oper. Res. 2019, 274, 837-844. [CrossRef]

31. Verma, S.; Mukherjee, V. Investigation of static transmission expansion planning using the symbiotic organisms search algorithm. Eng. Optim. 2018, 50, 1544-1560. [CrossRef]

32. De Oliveira, E.J.; Moraes, C.A.; Oliveira, L.W.; Honório, L.M.; Poubel, R.P.B. Efficient hybrid algorithm for transmission expansion planning. Electr. Eng. 2018, 100, 2765-2777. [CrossRef]

33. Fitiwi, D.Z.; Olmos, L.; Rivier, M.; De Cuadra, F.; Pérez-Arriaga, I.J. Finding a representative network losses model for large-scale transmission expansion planning with renewable energy sources. Energy 2016, 101, 343-358. [CrossRef]

34. Wu, W.; Hu, Z.; Song, Y.; Sansavini, G.; Chen, H.; Chen, X. Transmission network expansion planning based on chronological evaluation considering wind power uncertainties. IEEE Trans. Power Syst. 2018, 33, 4787-4796. [CrossRef]

35. Papaemmanouil, A.; Tjernberg, L.B.; Tuan, L.A.; Andersson, G. Improved cost-benefit analysis for market-based transmission planning, a European perspective. Energy Policy 2013, 63, 215-223. [CrossRef]

36. Dedecca, J.G.; Hakvoort, R.A.; Herder, P.M. Transmission expansion simulation for the European northern seas offshore grid. Energy 2017, 125, 805-824. [CrossRef]

37. Abbasi, S.; Abdi, H.; Bruno, S.; La Scala, M. Transmission network expansion planning considering load correlation using unscented transformation. Int. J. Electr. Power Energy Syst. 2018, 103, 12-20. [CrossRef]

38. Cole, S.; Martinot, P.; Rapoport, S.; Papaefthymiou, G. Cost-benefit analysis of a coordinated grid development in the North Sea. In Proceedings of the 2015 IEEE Eindhoven PowerTech, Eindhoven, The Netherlands, 29 June-2 July 2015.

39. Jaehnert, S.; Wolfgang, O.; Farahmand, H.; Völler, S.; Huertas-Hernando, D. Transmission expansion planning in northern Europe in 2030-Methodology and analyses. Energy Policy 2013, 61, 125-139. [CrossRef] 
40. Vandyshev, K.; de Graaff, S.D.A.; van Casteren, J.; Klaar, D. Using optimized flow based market capacity indices in TSO investment evaluation. In Proceedings of the 13th International Conference on the European Energy Market (EEM), Porto, Portugal, 6-9 June 2016.

41. Dicorato, M.; Tricarico, G.; Trovato, M.; Forte, G.; Bronzini, M. Techno-economic benefit of network developments: A flow-based evaluation. In Proceedings of the 55th International Universities Power Engineering Conference (UPEC), Turin, Italy, 1-4 September 2020.

42. Lumbreras, S.; Ramos, A. The new challenges to transmission expansion planning. Survey of recent practice and literature review. Electr. Power Syst. Res. 2016, 134, 19-29. [CrossRef]

43. Mahdavi, M.; Antunez, C.S.; Ajalli, M.; Romero, R. Transmission expansion planning: Literature review and classification. IEEE Syst. J. 2018, 13, 3129-3140. [CrossRef]

44. Armando, L.A.F.; Andres, G.J. Transmission explation planning: A discussion on reliability and "N-1" security criteria. In Proceedings of the IEEE 11th International Conference on Probabilistic Methods Applied to Power Systems (PMAPS), Singapore, 14-17 June 2010.

45. Tor, O.B.; Guven, A.N.; Shahidehpour, M. Promoting the investment on IPPs for optimal grid planning. IEEE Trans. Power Syst. 2010, 25, 1743-1750. [CrossRef]

46. 2nd ENTSO-E Guideline for Cost Benefit Analysis of Grid Development Project. Available online: https://www.entsoe.eu/news / 2018/10/12/commission-approves-2d-entso-e-guideline-for-cost-benefit-analysis-of-grid-development-projects / (accessed on 3 May 2021).

47. Metodologia Analisi Costi-Benefici-ACB 2.0. Available online: https:/ / download.terna.it/terna/0000/1009/13.pdf (accessed on 3 May 2021). (In Italian).

48. Ho, W.; Ma, X. The state-of-the-art integrations and applications of the analytic hierarchy process. Eur. J. Oper. Res. 2018, 267, 399-414. [CrossRef]

49. Thomas, L.S. The Analytic Hierarchy Process: Planning, Priority Setting, Resource Allocation; McGraw-Hill: New York, NY, USA, 1980.

50. Meza, J.L.C.; Yildirim, M.B.; Masud, A.S. A multiobjective evolutionary programming algorithm and its applications to power generation expansion planning. IEEE Trans. Syst. Man Cybern.Part A Syst. Hum. 2009, 39, 1086-1096. [CrossRef]

51. Malkawi, S.; Azizi, D. A multi-criteria optimization analysis for Jordan's energy mix. Energy 2017, 127, 680-696. [CrossRef]

52. Jing, R.; Zhu, X.; Zhu, Z.; Wang, W.; Meng, C.; Shah, N.; Zhao, Y. A multi-objective optimization and multi-criteria evaluation integrated framework for distributed energy system optimal planning. Energy Convers. Manag. 2018, 166, 445-462. [CrossRef]

53. Gardeshi, M.E.; Rahimi-Kian, A. Invasive weed optimization feature in market-based transmission expansion planning. In Proceedings of the 16th International Conference on Intelligent System Applications to Power Systems, Hersonissos, Greece, 25-28 September 2011.

54. Majumder, S.; Shereef, R.M.; Khaparde, S.A. Two-stage algorithm for efficient transmission expansion planning with renewable energy resources. IET Renew. Power Gener. 2017, 11, 320-329. [CrossRef]

55. Liang, L.U.; Hong, Z.; ShaoRong, C.; YiBen, L.; Li, J.; YuHong, W. Comprehensive evaluation of transmission network planning schemes based on IFAHP. In Proceedings of the 4th International Conference on HVDC, Xi'an, China, 6-9 November 2020.

56. Moghaddam, S.Z.; Monsef, H.; Jafari, M. A new heuristic method for transmission expansion planning using AHP. In Proceedings of the 10th International Conference on Environment and Electrical Engineering, Rome, Italy, 8-11 May 2011.

57. Zhao, H.; Liu, H.; You, D.; Zhao, X. Comprehensive evaluation index system for screening and sequencing power transmission grid planning projects. In Proceedings of the 10th Asia-Pacific Power and Energy Engineering Conference (APPEEC), DEStech Transactions on Environment, Energy and Earth Sciences, Guilin, China, 20-22 April 2018.

58. Neto, E.A.; Coelho, J.; Camargo, C.C.B.; Rodigheri, A.; Reis, M.M.; Cimino, L.; Reinig, A.O. An AHP multiple criteria model applied to transmission expansion of a Brazilian southeastern utility. In Proceedings of the 2010 IEEE/PES Transmission and Distribution Conference and Exposition: Latin America (T\&D-LA), Sao Paulo, Brazil, 8-10 November 2010.

59. González, A.; RodrÍguez, J.; Fernández, F.; Blanco, G.; Oxilia, V. Multi-criteria analysis of the expansion plan of the transmission system of Paraguay. In Proceedings of the 2019 IEEE CHILEAN Conference on Electrical, Electronics Engineering, Information and Communication Technologies (CHILECON), Valparaiso, Chile, 29-31 October 2019.

60. Frank, S.; Steponavice, I.; Rebennack, S. Optimal power flow: A bibliographic survey I. Energy Syst. 2012, 3, 221-258. [CrossRef]

61. Vlachos, A.G.; Biskas, P.N. Adjustable profile blocks with spatial relations in the day-ahead electricity market. IEEE Trans. Power Syst. 2013, 28, 4578-4587. [CrossRef]

62. Dourbois, G.A.; Biskas, P.N.; Vlachos, A.G. A new concept for the clearing of European Power exchange day-ahead markets with complex orders. In Proceedings of the 11th International Conference on the European Energy Market (EEM14), Krakow, Poland, 28-30 May 2014.

63. Saaty, R.W. The analytic hierarchy process—what it is and how it is used. Math. Model. 1987, 9, 161-176. [CrossRef]

64. Vaidya, O.S.; Kumar, S. Analytic hierarchy process: An overview of applications. Eur. J. Oper. Res. 2006, 169, 1-29. [CrossRef]

65. Pena, I.; Martinez-Anido, C.B.; Hodge, B.M. An extended IEEE 118-bus test system with high renewable penetration. IEEE Trans. Power Syst. 2017, 33, 281-289. [CrossRef]

66. An Extended IEEE 118-Bus Test System with High Renewable Penetration. Available online: https://item.bettergrids.org/ handle/1001/120 (accessed on 3 May 2021). 
67. Al-Shetwi, A.Q.; Sujod, M.Z. Grid-connected photovoltaic power plants: A review of the recent integration requirements in modern grid codes. Int. J. Energy Res. 2018, 42, 1849-1865. [CrossRef]

68. Wu, Y.K.; Chang, S.M.; Mandal, P. Grid-connected wind power plants: A survey on the integration requirements in modern grid codes. IEEE Trans. Ind. Appl. 2019, 55, 5584-5593. [CrossRef]

69. Deliverable 2.1.1 Guidelines for Coordinated Planning: (B) Survey and Tools for supporting the Harmonized Planning Process. Available online: https://www.med-tso.com/publications/Deliverable_2.1.1_Guidelines_for_Coordinated_Planning_b) Survey_and_Tools.pdf (accessed on 3 May 2021).

70. Planning Criteria for Future Transmission Networks in the Presence of a Greater Variability of Power Exchange with Distribution Systems. Available online: https:/ /e-cigre.org/publication/681-planning-criteria-for-future-transmission-networks-in-thepresence-of-a-greater-variability-of-power-exchange-with-distribution-systems (accessed on 3 May 2021).

71. Zimmerman, R.D.; Murillo-Sánchez, C.E.; Thomas, R.J. MATPOWER: Steady-state operations, planning, and analysis tools for power systems research and education. IEEE Trans. Power Syst. 2010, 26, 12-19. [CrossRef]

72. Terna. Conventional Technical Solution for the Connection to Main Power System-Average Grid Component Costs Report. Available online: http:/ / www.terna.it (accessed on 27 June 2020). (In Italian).

73. ACER. Report on Unit Investment Cost Indicators and Corresponding Reference Values for Electricity and Gas InfrastructureElectricity Infrastructure Ref: 15-Infrastructure Unit Investment Costs-ELEC-2015, Version 1.1. 2015. Available online: http: / / www.acer.europa.eu (accessed on 27 June 2020).

74. Alonso, J.A.; Lamata, M.T. Estimation of the random index in the analytic hierarchy process. In Proceedings of the 10th Conference of Information Processing and Management of Uncertainty in Knowledge-Based Systems, Perugia, Italy, 4-9 July 2004.

75. Franek, J.; Kresta, A. Judgment scales and consistency measure in AHP. Proc. Econ. Finance 2014, 12, 164-173. [CrossRef] 